University of Wollongong

Research Online

Australian Institute for Innovative Materials -

Papers

Australian Institute for Innovative Materials

$1-1-2019$

Design strategies for developing non-precious metal based bi-functional catalysts for alkaline electrolyte based zinc-air batteries

Chao Han

University of Wollongong, chan@uow.edu.au

Weijie Li

University of Wollongong,weijie@uow.edu.au

Hua-Kun Liu

University of Wollongong, hua@uow.edu.au

Shi Xue Dou

University of Wollongong, shi@uow.edu.au

Jiazhao Wang

University of Wollongong, jiazhao@uow.edu.au

Follow this and additional works at: https://ro.uow.edu.au/aiimpapers

Part of the Engineering Commons, and the Physical Sciences and Mathematics Commons

Research Online is the open access institutional repository for the University of Wollongong. For further information contact the UOW Library: research-pubs@uow.edu.au 


\title{
Design strategies for developing non-precious metal based bi-functional catalysts for alkaline electrolyte based zinc-air batteries
}

\author{
Abstract \\ Compared with the current dominant energy storage system (lithium-ion batteries (LIBs)), rechargeable \\ zinc-air batteries (ZABs) with alkaline electrolyte are safer and less expensive, have much higher \\ theoretical volumetric energy density, can be manufactured in ambient air rather than a dry room, and \\ have much higher tolerance to moisture and air during operation. A mature aqueous alkaline electrolyte \\ could also significantly improve safety while minimizing the fabrication cost. Hence, ZABs have great \\ potential to challenge the dominant position of LIBs in the future. Nevertheless, the widespread \\ application of this energy storage system is seriously hindered by the sluggish kinetics of the oxygen \\ reduction (ORR) and evolution reactions (OER) at the liquid-gas-solid phase cathode interface. Therefore, \\ to further promote the development of this technology, the development of low-cost, high-activity \\ catalysts for the OER/ORR has long been recognized as a crucial measure. This paper summarizes the \\ existing strategies that could be used to develop non-precious-metal based, high activity bifunctional \\ OER/ORR catalysts for the alkaline electrolyte based zinc-air system.

\section{Disciplines} \\ Engineering | Physical Sciences and Mathematics

\section{Publication Details} \\ Han, C., Li, W., Liu, H., Dou, S. \& Wang, J. (2019). Design strategies for developing non-precious metal \\ based bi-functional catalysts for alkaline electrolyte based zinc-air batteries. Materials Horizons, 6 (9), \\ 1812-1827.
}




\section{Design Strategy of Non-precious Metal Based Bi-functional Catalysts for the Alkaline based Zinc-Air Battery}

Received 00th January 20xx, Accepted 00th January 20xx DOI: $10.1039 / x 0 x \times 00000 x$

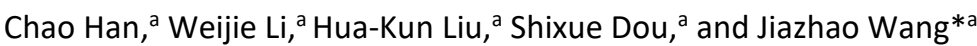

Comparing with current dominant energy storage system -- lithium-ion batteries (LIBs), rechargeable Zinc-Air batteries (ZABs) with alkaline based electrolyte are safer and less expensive; have much higher theoretical volumetric energy density; could be manufactured in ambient air rather than a dry room, and have much higher tolerance to moisture and air during operation. The mature aqueous alkaline electrolyte could also significantly improve safety while minimizing the fabrication cost. Hence ZABs have great potential to challenge the dominant position of LIBs in future. Nevertheless, wide application of this energy storage system is seriously hindered by the sluggish kinetics of the oxygen reduction (ORR) and evolution reactions (OER) at the liquid-gas-solid phase cathode interface. Therefore, to further promote the development of this technology, the development of low-cost, high-activity catalysts for the OER/ORR has long been recognized as a crucial measure. This paper summarizes existing strategies that could be taken to develop non-precious-metal based, high activity bifunctional OER/ORR catalysts for the alkaline electrolyte based Zinc-Air system.
\end{abstract}

\section{Introduction}

With the growing demands for electricity usage in transportation, industry, and daily life, sources of fossil fuel energy such as coal, natural gas, and petroleum are being depleted more quickly. The development of zero-emission electrical vehicles, high-efficiency smart grids, and green renewable energy has been a common sense approach for humanity to address the energy crisis and fossil-fuel pollution. As one of the core technologies, however, the ongoing research on advanced energy storage system has always been inadequate for further development in these areas. The current dominant contender in the commercial energy storage market is still non-aqueous lithium-ion batteries (LIBs), which have high energy density and long cycle life, but are expensive and dangerous because of limited lithium resources and the air sensitivity of electrolyte and lithium. Compared with LIBs, rechargeable aqueous Zinc-Air batteries (ZABs) are much safer and lower cost; they could be manufactured in ambient air rather than a dry room, and they have much higher tolerance to moisture and air during operation. ${ }^{1-4}$ Aqueous electrolyte could be used in ZABs, thereby significantly improving their safety while minimizing the fabrication cost. Moreover, the theoretical volumetric energy density (4400 Wh. $\left.\mathrm{L}^{-1}\right)$ and specific energy density (180-200 Wh. $\mathrm{kg}^{-1}$ ) of $\mathrm{Zn}$-Air batteries is three times and 1.1 times greater than for conventional Li-ion batteries (1400 Wh. $\mathrm{L}^{-1}$ and $\left.160 \mathrm{Wh} \cdot \mathrm{kg}^{-1}\right) \cdot{ }^{5-12}$ Figure 1 provides a

a. Institute for Superconducting and Electronic Materials, AIIM Building, Innovation Campus, University of Wollongong, Squires Way, North Wollongong, NSW2500, Australia.

Corresponding Email is comparison of the specific and volumetric energy density of ZABs with those of different families of batteries and electrical double layer capacitors (EDLCs).

Table 1 briefly compares the cost and cycle life of different kinds of energy storage systems existing on the market, from which it is easy to conclude that ZABs have unmatched low cost comparing with other existing commercial energy-storage systems.

The aqueous alkaline electrolyte based $Z A B$ is a relatively mature technology and holds the greatest promise for future energy applications. Its primary batteries have been known si-

Table 1. Comparison of the technical characteristics of $\mathrm{Zn}$-Air battery and other mature developed battery energy storage systems. $5,13-23$

\begin{tabular}{ccccc}
\hline & Zn-Air & Pb-Acid & Ni-Cd & Li ion \\
\hline Anode & $\mathrm{ZnO} / \mathrm{Zn}$ & $\mathrm{Pb}$ & $\mathrm{Cd}$ & Graphite \\
Cathode & $\mathrm{Air}$ & $\mathrm{PbO}_{2}$ & $\mathrm{NiOOH}$ & $\mathrm{LiCoO}_{2}$ \\
Electrolyte & Alkaline & Acid & Alkaline & Organic \\
Efficiency & 50 & $75-90$ & $65-90$ & $>95$ \\
(\%, average) & & & & \\
Wh.kg-1 & $180-200$ & $30-50$ & $10-75$ & 160 \\
W.kg-1 & 200 & $75-300$ & $150-300$ & 400 \\
Cycle life & 200 & $200-$ & $300-$ & $>1000$ \\
(C-rate) & $(0.067 \mathrm{C})$ & 2500 & 2500 & \\
Storage & Hours- & Minutes- & Minutes- & Minutes- \\
durability & months & days & days & days \\
Cost (\$/kWh) & $10-400$ & $200-700$ & $400-$ & $500-$ \\
& & & 1500 & 2500 \\
Cost/cycle & $3-5$ & $25-107$ & $20-115$ & $15-100$ \\
(Cents/kWh/cycl & & & &
\end{tabular}



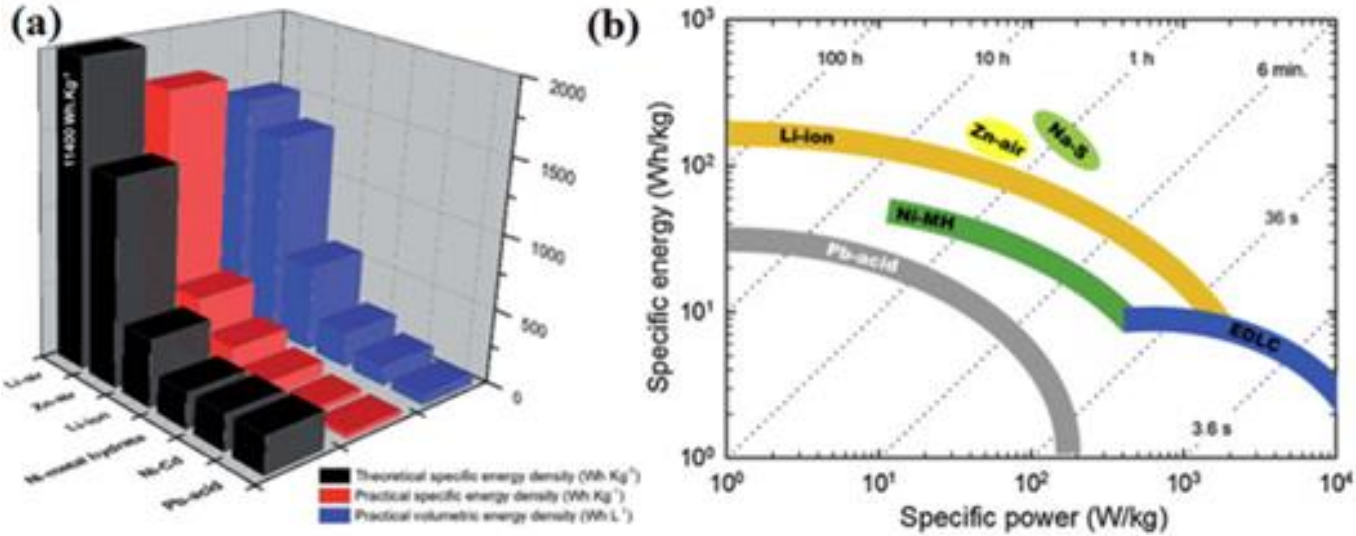

Figure 1. Comparison of ZABs with different power systems: (a) Theoretical/Practical/Volumetric energy density; ${ }^{24}$ Copyright 2018 , Royal Society of Chemistry. (b) Specific energies versus power densities (Ragone plot), with EDLC representing supercapacitors. ${ }^{25}$ Copyright 2014, Elsevier Limited.

-nce the late nineteenth century, and commercial products started to emerge in the 1930s. ${ }^{26}$ With rising awareness of the need for environmental protection and the growing popularity of electric vehicles, attempts to use ZABs in electric vehicles began in 1999. Electric Fuel Ltd. (EFL) has developed a highenergy zinc-air battery system, designed to allow electric vehicles to compete with conventional vehicles in price, performance, convenience, and safety, while offering superior range, highway speeds, equivalent cargo capacity, and quick refueling. ${ }^{27-32}$ Nevertheless, one big obstacle for the wide application of rechargeable ZABs is their limited energy efficiency and poor cycling stability, 20, 23, 33-38 which originates from the irreversible consumption of zinc anode and sluggish oxygen evolution/reduction reactions (OER/ORR) that take place on the gas-liquid-solid interface of the oxygen electrode in alkaline electrolyte. Hence, the development of high-activity bifunctional (OER/ORR) catalysts has long been recognized as an efficient and necessary measure to enable further flourishing of the rechargeable Zn-Air battery market, which has high potential for replacing the lithium ion battery. Although there have been a huge number of review papers on bifunctional OER/ORR catalysts, 9, 24, 39-43 we briefly summarize the state of the art strategies that were used to further boost the performance of bifunctional catalysts with alkaline electrolyte.

\section{Working Principles and Mechanisms of ZABs}

Generally, typical primary and rechargeable alkaline electrolyte based ZABs are both composed of a zinc anode, alkaline aqueous electrolyte ( $6 \mathrm{M} \mathrm{KOH}$ and $\left.0.2 \mathrm{M} \mathrm{Zn}\left(\mathrm{CH}_{3} \mathrm{COO}\right)_{2}\right)$, and a catalyst containing air electrode. The merits of alkaline electrolyte and other possible electrolyte systems have been well reviewed by Blazquez et al.. ${ }^{20}$ The basic structure and reaction mechanisms of alkaline electrolyte-based rechargeable ZABs are shown in Figure 2(a).

The reactions at each side are as follows: Anode:

$$
\begin{aligned}
& \mathrm{Zn}_{(s)}+4 \mathrm{OH}_{(a q)}^{-} \rightarrow \mathrm{Zn}(\mathrm{OH})_{4(a q)}^{2-}+2 e^{-}\left(E^{0}=\right. \\
& -1.25 \mathrm{~V} \text { vs. } \mathrm{SHE}) \quad(1) \\
& \mathrm{Zn}(\mathrm{OH})_{4(a q)}^{2-} \rightarrow \mathrm{ZnO}_{(s)}+2 \mathrm{OH}_{(a q)}^{-}+\mathrm{H}_{2} \mathrm{O}_{(a q)} \\
& \text { Cathode: } \\
& \mathrm{O}_{2(g)}+2 \mathrm{H}_{2} \mathrm{O}_{(a q)}+4 e^{-} \rightarrow 4 O \mathrm{OH}_{(a q)}^{-}\left(E^{0}=\right. \\
& +0.401 \mathrm{~V} \text { vs. SHE) }
\end{aligned}
$$

Overall reaction:

$2 \mathrm{Zn}_{(s)}+\mathrm{O}_{2(\mathrm{~g})} \rightarrow 2 \mathrm{ZnO} \mathrm{O}_{(\mathrm{s})}($ Cell potential: $1.65 \mathrm{~V})(4)$

Side Reactions:

$2 \mathrm{KOH}_{(a q)}+\mathrm{CO}_{2(g)} \rightarrow \mathrm{K}_{2} \mathrm{CO}_{3(s)}+\mathrm{H}_{2} \mathrm{O}_{(a q)}$ (5)

$\mathrm{Zn}_{(\mathrm{s})}+2 \mathrm{H}_{2} \mathrm{O}_{(\mathrm{aq})} \rightarrow \mathrm{Zn}(\mathrm{OH})_{2(a q)}+\mathrm{H}_{2(\mathrm{~g})}$ (6)

$E^{0}$ is the potential of the electrochemical reaction, and SHE is standard hydrogen electrode. The theoretical reversible potential for ZABs is $1.65 \mathrm{~V}$ [Reaction (4)]. Depending on the applied current density, however, the practical voltage can drop to below $1.4 \mathrm{~V}$. The origin of this discharge potential drop is largely due to the high overpotential at the air electrode during the ORR (discharge). The charge (OER) potential is usually above $1.6 \mathrm{~V}$. Thus, rechargeable ZABs usually have low round-trip energy efficiency below 55-65\%. The main function of the catalysts on the air electrode is, therefore, to facilitate the OER and ORR during charge and discharge process, and increase the energy efficiency. By nature, the corresponding discharge (ORR) and charge (OER) reactions at the cathode of alkaline ZABs are interfacial and include a series of complex electron transfer reactions, involving a four electron reaction steps. In alkaline ZABs, the detailed ORR/OER procedure is schematically presented by Figure 2(b), which includes Reactions (7)-(10). Generally, the four-electron ORR proceeds through the formation of ${ }^{*} \mathrm{OOH}$ from adsorbed $\mathrm{O}_{2}$, followed by its further reduction to ${ }^{*} \mathrm{O}$ and $* \mathrm{OH}$, in which * refers to active sites on the catalyst. The OER (charge) procedure takes place just in the opposite sequence, e.g. from (10) to (7).

$*+\mathrm{O}_{2(\mathrm{~g})}+\mathrm{H}_{2} \mathrm{O}_{(\mathrm{l})}+e^{-} \leftrightarrow * \mathrm{OOH}+\mathrm{OH}^{-}$(7)

$* \mathrm{OOH}+e^{-} \leftrightarrow * \mathrm{O}+\mathrm{OH}^{-}$(8)

$* \mathrm{O}+\mathrm{H}_{2} \mathrm{O}_{(l)}+e^{-} \leftrightarrow * O H+\mathrm{OH}^{-}$(9)

$* O H+e^{-} \leftrightarrow \mathrm{OH}^{-}+*(10)$ 

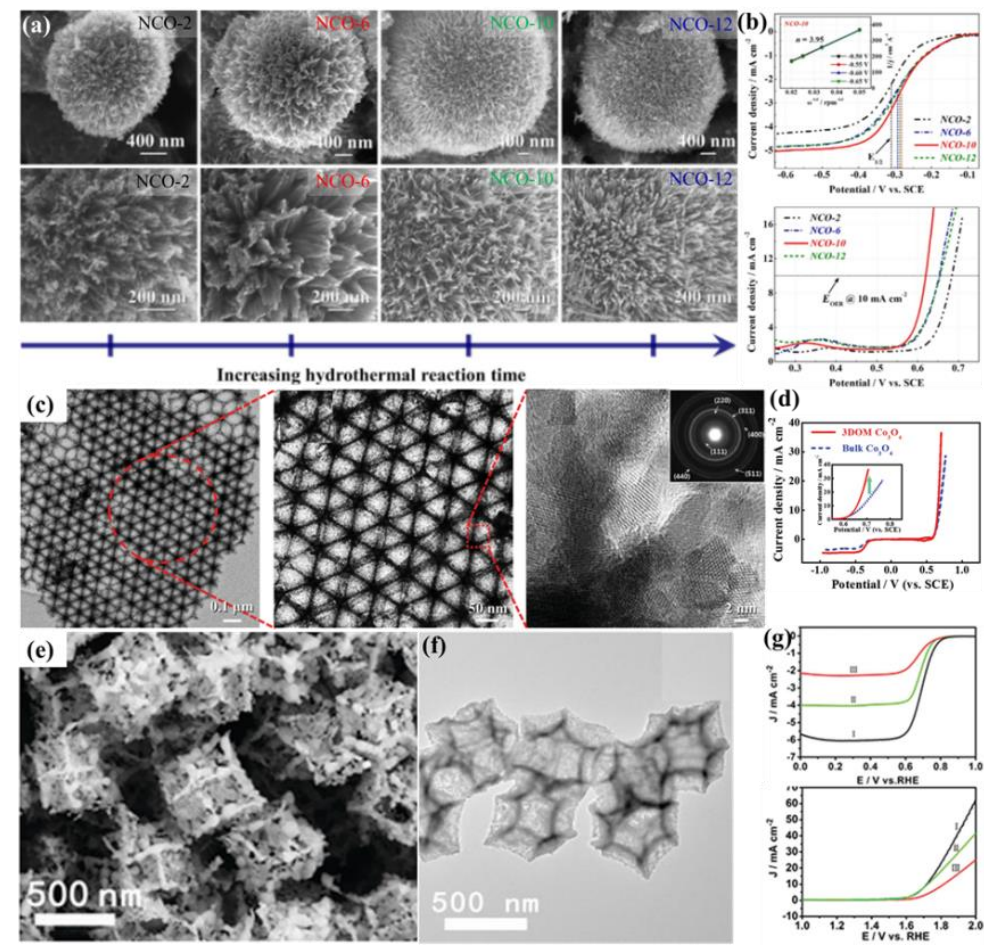

Figure 2. (a) Model and reaction mechanism in ZABs; 44 Copyright 2017, Elsevier Limited. (b) Schematic of ORR (Blue Path) and OER (Brown Path) procedure in alkaline solution; (c) ORR (Left) and OER (Right) volcano plot for metal oxides. ${ }^{41}$ Copyright 2017, The American Association for the Advancement of Science (AAAS) publishing group. (d) Schematic diagram of $E_{10}, E_{1 / 2}$, and $\Delta E$ during the OER and ORR. $E_{10}$ : potential needed to achieve current density $(J)$ of $10 \mathrm{~mA} \cdot \mathrm{cm}^{-2}$ during the OER; $E_{1 / 2}$ : half-wave potential for the ORR; RHE: reversible hydrogen electrode.

The potential for each step in Reactions (7)-(10) is determined by the difference in binding energy of the different intermediates (i.e., $* \mathrm{OH}, * \mathrm{O}$, and $* \mathrm{OOH}$ ) before and after a charge transfer. As demonstrated in Figure 2(c), currently, the best unifunctional catalysts for the OER and ORR are still the expensive noble metal catalysts $\mathrm{Ru} / \mathrm{IrO}_{2}$ and $\mathrm{Pt}$, respectively. ${ }^{4,45}$ Besides their high prices, the stability of these two noble metal catalysts is also fairly poor, besides the low tolerance of $\mathrm{Pt}$ towards methanol. Compared with the unifunctional ORR/OER electrocatalysts, bifunctional catalysts are more attractive due to their convenience and low cost. The main obstacle, however, to achieve bifunctional catalytic activity towards the OER and ORR in one material lies in the interdependence of the adsorption energy towards $\mathrm{OH}$ groups and $\mathrm{O}_{2}$ molecules [Reactions (7) and (9), or the Gibbs free energies $\left(\Delta G_{1}\right.$ and $\left.\Delta G_{3}\right)$ of the first and third reaction]. The scaling relations (interdependence) between the ${ }^{*} \mathrm{OH}$ and ${ }^{*} \mathrm{OOH}$ binding energies prevent any compound with a single site to be both ORR and OER active. ${ }^{46}$ Hence, intrinsically, as shown in Figure 3, to achieve bifunctional activity in one material, it is necessary to achieve a good balance between the formation energies of ${ }^{*} \mathrm{OH}$ and $* \mathrm{OOH}$ intermediates via the material structure, composition, and design of electronic states.

To characterize the bifunctional catalytic activity, the potential difference $(\Delta E)$ between the potential for achieving current density of $10 \mathrm{~mA} \cdot \mathrm{cm}^{-2}$ during the OER reaction $\left(E_{10}\right)$ and the half-wave potential $\left(E_{1 / 2}\right)$ during the ORR reaction has been calculated, which is schematically shown in Figure 2(d). Table 2 briefly summarizes some typical, high-performance $(\Delta E<1.0 \mathrm{~V})$, catalysts that are bifunctional for both the ORR and the OER in alkaline solution, which could be generally divided into the following three groups: transition metals; transition metal compounds, including oxides, sulphides, hydroxides, nitrides and phosphides; and carbon-based materials. ${ }^{24,} 39,47$ Transition metal compounds offer a good foundation for achieving bifunctional results due to the following reasons: (1) transition metals and corresponding ions have unfilled $3 d$ orbitals, leading to variable and adjustable cationic oxidation states. Since the ORR and OER procedures both involve a redox reaction, catalysts with variable cationic states are predicted to possess good stability. (2) Moreover, variable structures of transition metal compounds provide excellent scaffolds to achieve suitable affinity for oxygen absorption and electronic structures. Moreover, the detailed OER/ORR catalytic mechanisms in alkaline solution for transition metal sulphides, phosphides, and nitrides are still unclear, but some reports have proved that they are all related to the formation of an amorphous oxide layer outside the transition metal compound. ${ }^{48-49}$

Unlike the transition metal compounds, carbon based materials also constitute a group of bifunctional catalysts because of their 
high electrical conductivity, structural variety, and rich heteroatom doping or defects chemistry.
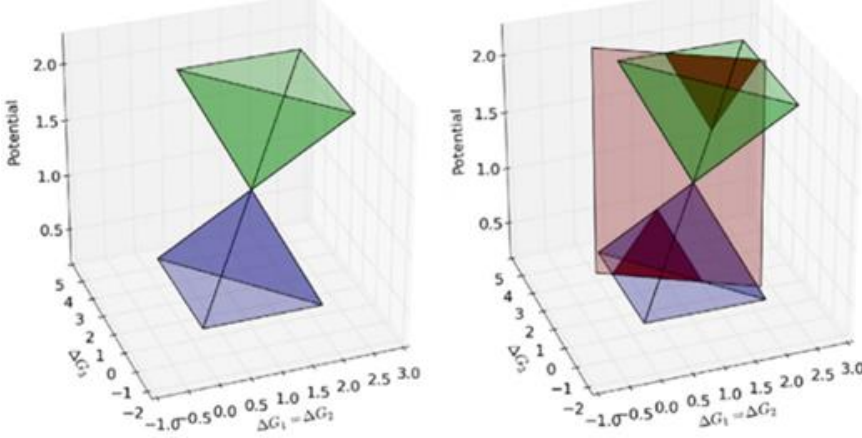

Figure 3. Two pyramids depicting the best achievable potential for the ORR (blue) and the potential of the potential determining step for the OER (green) as a function of the first $\left(\Delta G_{1}\right)$ and the third reaction $\left(\Delta G_{3}\right)$ free energies. The constraint set by the constant offset of $3.2 \mathrm{eV}$ between ${ }^{*}-\mathrm{OH}$ and ${ }^{*}-\mathrm{OOH}$ is represented by the red plane. The red plane that cuts the two pyramids creates two separate volcanoes for the OER and the ORR, which are darkened. ${ }^{50}$ Copyright 2016, Elsevier Limited.

Compared with the bench mark $\mathrm{Pt} / \mathrm{C}$ and $\mathrm{RuO}_{2}$ systems, whose $\Delta \mathrm{E}$ is around $0.70 \mathrm{~V}$, most bifunctional catalysts are still unsatisfactory. Generally, increasing the number of active sites while increasing the intrinsic activity of each active site are recognized as the two basic principles for further enhancing catalytic activity for all catalysts. In more detail, this paper focuses on summarizing the most recent progress in detailed strategies to achieve these two objectives for further enhancing the intrinsic OER/ORR activities of the non-precious-metal based catalysts.

\section{Strategies for Further Enhance OER/ORR activities of the non-precious-metal based catalysts}

\subsection{Control of ion field intensity of transition metals}

Since the adsorption of $\mathrm{O}_{2}$ and $\mathrm{OH}^{-}$on the catalytic active sites is an electrostatic attraction, adjusting the intensity of the cationic ion field will definitely affect the ORR/OER processes. The ion field intensity is obtained from the ion radius divided by the valence and would be affected by neighboring atoms. Transition metals can lose electrons more readily than other elements because they have unstable electrons in their outer orbitals. Some oxidation states are more common for transition metals than for elements in the main groups. Moreover, the radius of transition metal ions also varies depending on their species and valence. Different anions and neighboring atoms could also have an impact on their oxidation states. Transition metal oxides containing highly oxidized redox couples such as $\mathrm{Ir}^{4+/ 6+}, \mathrm{Ru}^{4+/ 8+}, \mathrm{CO}^{3+/ 4+}, \mathrm{Ni}^{3+/ 4+}, \mathrm{Mn}^{3+/ 4+}$, and $\mathrm{Fe}^{3+/ 4+}$ are known as active centers for the OER. The electrochemical performance of oxides for the OER follows the orders, $\mathrm{IrO}_{2}>\mathrm{RuO}_{2}>\mathrm{Co}_{3} \mathrm{O}_{4}$ and $\mathrm{Ni}$-containing cobalt oxides $>\mathrm{Fe}, \mathrm{Pb}$, and $\mathrm{Mn}$ containing oxides. Among the numerous low-cost oxides investigated, cobalt and manganese oxides are promising for both the OER and the ORR due to their moderate ion field intensity. ${ }^{51}$

Table 2. Some state-of-the-art bifunctional ORR/OER catalysts in $0.1 \mathrm{M} \mathrm{KOH}$. CNT: carbon nanotube; rGO: reduced graphene oxide.

\begin{tabular}{|c|c|c|c|c|c|}
\hline Category & Catalyst & $\begin{array}{c}\mathrm{E}_{10}(\mathrm{OE} \\
\mathrm{R})\end{array}$ & $\begin{array}{c}E_{1 / 2}(O R \\
R)\end{array}$ & $\Delta \mathrm{E}$ & $\begin{array}{l}\text { Referen } \\
\text { ce }\end{array}$ \\
\hline \multirow{2}{*}{$\begin{array}{l}\text { Transitio } \\
\text { n Metal }\end{array}$} & Co-N-C & $1.54 \mathrm{~V}$ & $0.80 \mathrm{~V}$ & $\begin{array}{l}0.7 \\
4 \mathrm{~V}\end{array}$ & 52 \\
\hline & $\begin{array}{l}\text { (FeCoNi)@N- } \\
\text { graphene tube }\end{array}$ & $1.54 \mathrm{~V}$ & $0.89 \mathrm{~V}$ & $\begin{array}{l}0.6 \\
5 \mathrm{~V}\end{array}$ & 53 \\
\hline \multirow{6}{*}{$\begin{array}{c}\text { Transitio } \\
\text { n Metal } \\
\text { Oxides }\end{array}$} & $\mathrm{CoO}$ & $1.56 \mathrm{~V}$ & $0.85 \mathrm{~V}$ & $\begin{array}{l}0.7 \\
1 \mathrm{~V}\end{array}$ & 54 \\
\hline & $\begin{array}{c}\mathrm{Co}_{3} \mathrm{O}_{4} / \mathrm{N} \\
\text { doped } \\
\text { graphene }\end{array}$ & $1.60 \mathrm{~V}$ & $0.83 \mathrm{~V}$ & $\begin{array}{l}0.7 \\
7 \mathrm{~V}\end{array}$ & 55 \\
\hline & $\mathrm{NiCO}_{2} \mathrm{O}_{4}-\mathrm{CNT}$ & $1.66 \mathrm{~V}$ & $0.81 \mathrm{~V}$ & $\begin{array}{l}0.8 \\
5 \mathrm{~V}\end{array}$ & 56 \\
\hline & $\begin{array}{c}\mathrm{MnO}_{2} / \mathrm{N} \\
\text { doped CNT }\end{array}$ & $1.88 \mathrm{~V}$ & $1.05 \mathrm{~V}$ & $\begin{array}{l}0.8 \\
3 \mathrm{~V}\end{array}$ & 57 \\
\hline & $\mathrm{CoV}_{1.5} \mathrm{Fe}_{0.5} \mathrm{O}_{4}$ & $1.57 \mathrm{~V}$ & $0.74 \mathrm{~V}$ & $\begin{array}{l}0.8 \\
3 \mathrm{~V}\end{array}$ & 58 \\
\hline & $\begin{array}{r}\mathrm{La}_{\mathbf{x}}\left(\mathrm{Ba}_{0.5} \mathrm{Sr}_{0.5}\right)_{1-} \\
{ }_{x} \mathrm{Co}_{0.8} \mathrm{Fe}_{0.2} \mathrm{O}_{3-\delta}\end{array}$ & $1.60 \mathrm{~V}$ & $0.66 \mathrm{~V}$ & $\begin{array}{l}0.9 \\
4 \mathrm{~V}\end{array}$ & 59 \\
\hline \multirow{3}{*}{$\begin{array}{l}\text { Transitio } \\
\text { n Metal } \\
\text { Sulfide }\end{array}$} & $\begin{array}{l}\mathrm{NiCO}_{2} \mathrm{~S}_{4} @ S- \\
\text { graphene }\end{array}$ & $1.59 \mathrm{~V}$ & $0.90 \mathrm{~V}$ & $\begin{array}{l}0.6 \\
9 \mathrm{~V}\end{array}$ & 60 \\
\hline & $\mathrm{CuS} / \mathrm{NiS}_{2}$ & $1.62 \mathrm{~V}$ & $0.71 \mathrm{~V}$ & $\begin{array}{l}0.9 \\
1 \mathrm{~V}\end{array}$ & 61 \\
\hline & $\begin{array}{l}\mathrm{Cog}_{8} / \mathrm{N}, \mathrm{S} \\
\text { doped rGO }\end{array}$ & $1.55 \mathrm{~V}$ & $0.79 \mathrm{~V}$ & $\begin{array}{l}0.7 \\
6 \mathrm{~V}\end{array}$ & 62 \\
\hline $\begin{array}{c}\text { Transitio } \\
\text { n Metal } \\
\text { LDH }\end{array}$ & $\begin{array}{c}\mathrm{Co}(\mathrm{OH})_{2} / \mathrm{N}- \\
\mathrm{rGO}\end{array}$ & $1.66 \mathrm{~V}$ & $0.81 \mathrm{~V}$ & $\begin{array}{l}0.8 \\
5 \mathrm{~V}\end{array}$ & 63 \\
\hline \multirow{2}{*}{$\begin{array}{c}\text { Transitio } \\
\text { n Metal } \\
\text { Nitrides }\end{array}$} & $\mathrm{Ni}_{3} \mathrm{FeN}$ & $1.50 \mathrm{~V}$ & $0.50 \mathrm{~V}$ & $\begin{array}{l}1.0 \\
0 \mathrm{~V}\end{array}$ & 64 \\
\hline & $\begin{array}{l}\mathrm{Ni}_{3} \mathrm{FeN} / \mathrm{N}- \\
\text { doped } \mathrm{rGO}\end{array}$ & $1.63 \mathrm{~V}$ & $0.90 \mathrm{~V}$ & $\begin{array}{l}0.7 \\
3 \mathrm{~V}\end{array}$ & 65 \\
\hline \multirow{2}{*}{$\begin{array}{c}\text { Transitio } \\
\text { n Metal } \\
\text { Phosphi } \\
\text { de }\end{array}$} & $\begin{array}{c}\mathrm{Fe}_{0.33} \mathrm{CoP} @ \mathrm{Nic} \\
\text { kel foam }\end{array}$ & $1.54 \mathrm{~V}$ & $0.80 \mathrm{~V}$ & $\begin{array}{l}0.7 \\
4 \mathrm{~V}\end{array}$ & 66 \\
\hline & $\mathrm{Co}_{2} \mathrm{P}$ & $1.50 \mathrm{~V}$ & $0.84 \mathrm{~V}$ & $\begin{array}{l}0.6 \\
6 \mathrm{~V}\end{array}$ & 67 \\
\hline \multirow{2}{*}{$\begin{array}{c}\text { Carbon } \\
\text { Based }\end{array}$} & $\begin{array}{l}\mathrm{N} \text { doped } \\
\text { carbon } \\
\text { microtube }\end{array}$ & $1.52 \mathrm{~V}$ & $0.89 \mathrm{~V}$ & $\begin{array}{l}0.6 \\
3 \mathrm{~V}\end{array}$ & 68 \\
\hline & $\begin{array}{l}\text { P, N co-doped } \\
\text { graphene }\end{array}$ & $1.55 \mathrm{~V}$ & $0.85 \mathrm{~V}$ & $\begin{array}{l}0.7 \\
0 \mathrm{~V}\end{array}$ & 69 \\
\hline
\end{tabular}




\begin{tabular}{lllll}
\hline $\begin{array}{l}\text { Nanoporous } \\
\text { carbon fibre }\end{array}$ & $1.81 \mathrm{~V}$ & $0.81 \mathrm{~V}$ & $\begin{array}{l}1.0 \\
0 \mathrm{~V}\end{array}$ & 70 \\
\hline
\end{tabular}
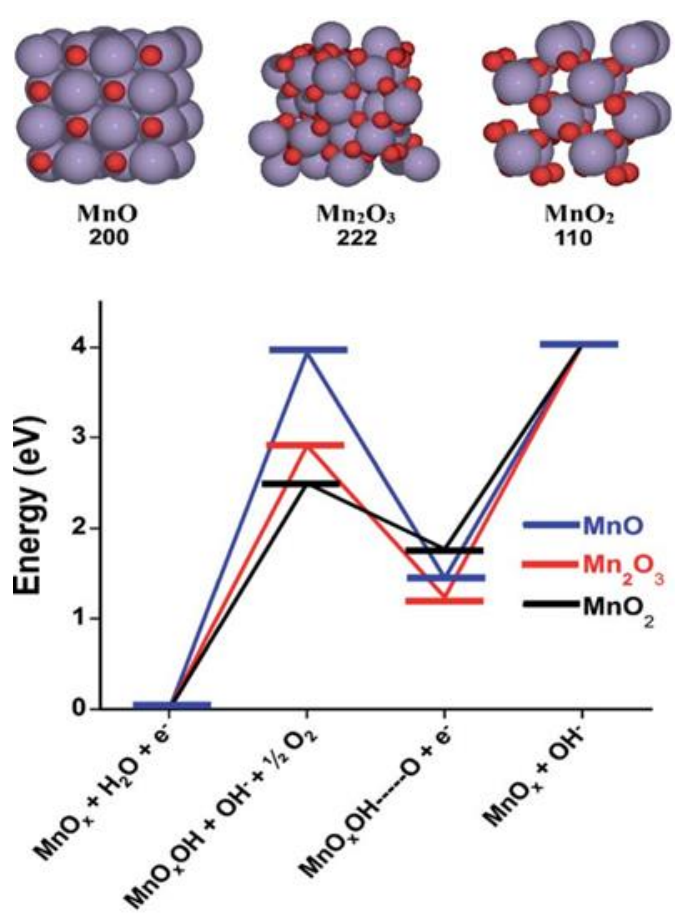

Figure 4. Bulk structure of $\mathrm{MnO}, \mathrm{Mn}_{2} \mathrm{O}_{3}$, and $\mathrm{MnO}_{2}$ (with the purple atoms $\mathrm{Mn}$ and the red ones $\mathrm{O}$ ); below are the calculated elementary reaction pathways for the dissociation of $\mathrm{H}_{2} \mathrm{O}$ on different kinds of manganese oxides. ${ }^{71}$ Copyright 2016, Royal Society of Chemistry.

Jaramillo et al. synthesized a novel $\mathrm{Mn}$ (III) oxide $\left(\mathrm{Mn}_{3} \mathrm{O}_{4}\right)$ film using the electrodeposition method, which demonstrated excellent bifunctional activity, with its individual ORR and OER activity comparable to the best reported metal oxides and even some precious metals materials. ${ }^{72-73}$ In-situ X-ray absorption spectroscopy (XAS) confirmed that a disordered $\mathrm{Mn}_{3}{ }^{\mathrm{II}, \mathrm{III}, \mathrm{II} \mathrm{O}_{4}}$ phase contributes to the ORR, while a mixed $\mathrm{Mn}^{\mathrm{II}, \mathrm{IV}}$ oxide is related to the OER. Hence, simply by tuning the $\mathrm{Mn}^{\prime \prime \prime} / \mathrm{Mn}^{\mathrm{IV}}$ ratio, OER/ORR catalytic activity is modified. Based on this concept, other similar analogues could also be bifunctional for the OER/ORR once the composition and valence state of the transition metal have been carefully designed. As seen from Figure 4, Suib's work also proved that $\mathrm{Mn}$ in different oxidation states showed different catalytic activity towards the ORR and OER reactions, while the activity was slightly enhanced as the percentage of $\mathrm{Mn}^{3+}$ increased when the calcination temperature was increased to $350{ }^{\circ} \mathrm{C} .{ }^{71}$ Porous, bifunctional $\mathrm{NiFeO}_{x}$-based electrocatalysts were also synthesized using the hydrothermal - calcination in air method, while heat treatment at different temperatures resulted in well dispersed nanorod structures with high surface areas and mixed chemical states of $\mathrm{Ni}$ ions in the spinel structure. The sample annealed at $250^{\circ} \mathrm{C}$ showed the best OER/ORR performance due to its suitable mixed oxidation state of $\mathrm{Ni}^{.74}$

In general, variation of ion field intensities leads to electrostatic affinity tuning towards intermediates produced during OER/ORR. Precise control over the surface valence state of a ubiquitous electrocatalyst opens up new avenues in the field of alternative energy applications in terms of offering suitable lowcost and earth-abundant metal oxides. The most widely used strategy for achieving different oxidation states is by hydrothermal or chemical-based methods.

\subsection{Morphology Engineering}

As aforementioned, the OER/ORR reaction is actually an interfacial process, so morphology engineering could significantly affect the catalytic activity. Several strategies could be proposed based this point.

\subsubsection{Create Nanostructures with High Surface Area using Core-Shell or Porous Structures}

To further enhance the catalytic activity of bifunctional catalysts, one of the most direct and effective strategies is to expose more active sites via creating nanostructures with high surface area using core-shell or porous structures. ${ }^{75-82}$ This strategy is universe for enhancing catalytic activity of almost all catalysts.

As an example, $\alpha-\mathrm{MnO}_{2}$ nanospheres and nanowires were reported to outperform their microparticle counterpart, due to their smaller size and higher specific surface areas. ${ }^{83}$ Also, Chen et al. reported the synthesis of hierarchical mesoporous $\mathrm{CO}_{3} \mathrm{O}_{4}$ nanowire arrays as a highly efficient bifunctional ORR/OER catalyst, unlike other morphologies. ${ }^{78}$ Under current density of $50 \mathrm{~mA} \cdot \mathrm{cm}^{-2}$, the $\mathrm{ZAB}$ based on $\mathrm{CO}_{3} \mathrm{O}_{4}$ nanowire arrays showed an open circuit voltage of $1 \mathrm{~V}$ and a charge potential at $2 \mathrm{~V}$. Remarkable charge and discharge potential retentions ( $97 \%$ and $94 \%$, respectively) were shown even after 100 cycles (nearly a month). ${ }^{78}$ Qiao et al. reported the synthesis of porous $\mathrm{Co}_{3} \mathrm{O}_{4}$ nanowire arrays directly grown on $\mathrm{Cu}$ foil, which exhibited higher OER activity $\left(10.0 \mathrm{~mA} \mathrm{~cm} \mathrm{~cm}^{-2}\right.$ at $1.52 \mathrm{~V}$ in $0.1 \mathrm{M} \mathrm{KOH}$ solution), more favorable kinetics, and stronger durability in comparison to those of $\mathrm{IrO}_{2} / \mathrm{C} .{ }^{84}$ Figure $\mathbf{5}(\mathrm{a}-\mathrm{b})$ displays the morphology and OER/ORR curves of synthesized chestnut-like $\mathrm{NiCO}_{2} \mathrm{O}_{4}$ spinels (NCO) using the hydrothermal method. The products showed different morphologies and specific areas with different hydrothermal times, while their NCO-10 sample demonstrated the best OER/ORR performance in $0.1 \mathrm{M} \mathrm{KOH} .{ }^{79}$ Compared with bulk $\mathrm{CO}_{3} \mathrm{O}_{4}$, three-dimensional (3D) ordered porous $\mathrm{CO}_{3} \mathrm{O}_{4}$ showed obviously improved OER/ORR performance, as presented in Figure 5(c-d). ${ }^{85}$ Threedimensional (3D) ordered porous $\mathrm{CO}_{3} \mathrm{O}_{4}$ based $\mathrm{ZABs}$ also exhibited higher discharge and lower charge potential at 1.24 and $2.0 \mathrm{~V}$ at $10 \mathrm{~mA} \cdot \mathrm{cm}^{-2}$, respectively; as well as good durability within 200 cycles. Besides the porous structure, hollowstructured transition metal oxides offer low overpotential, a fast reaction rate, and excellent stability in oxygen related reactions, including the OER/ORR in metal-air battery systems. Recent progress in the oxygen-related catalysis of hollowstructured transition metal oxides has been summarized by Feng et al.. ${ }^{86}$ One of the typical examples is illustrated in Figure $5(\mathrm{e}-\mathrm{g})$. Bai et al. prepared $\mathrm{MnCo}_{2} \mathrm{O}_{4.5}$ nanoframes using carbonization of $\mathrm{Mn}$ doped zeolitic imidizolate framework-67 (ZIF-67) template. Linear sweep voltammetry (LSV) results showed that the hollowed-out $\mathrm{MnCo}_{2} \mathrm{O}_{4.5}$ exhibited improved OER/ORR performance compared to the $\mathrm{MnCo}_{2} \mathrm{O}_{4.5}$ nanocages due to higher specific surface area. ${ }^{75}$

\subsubsection{Morphology Design to Expose More Active Surface}


Usually, different facets in crystals have different arrangements of atoms, leading to differences in $\Delta \mathrm{G}_{1} \sim \Delta \mathrm{G}_{4}$ and finally fluctuation in OER/ORR catalytic activity. This point has
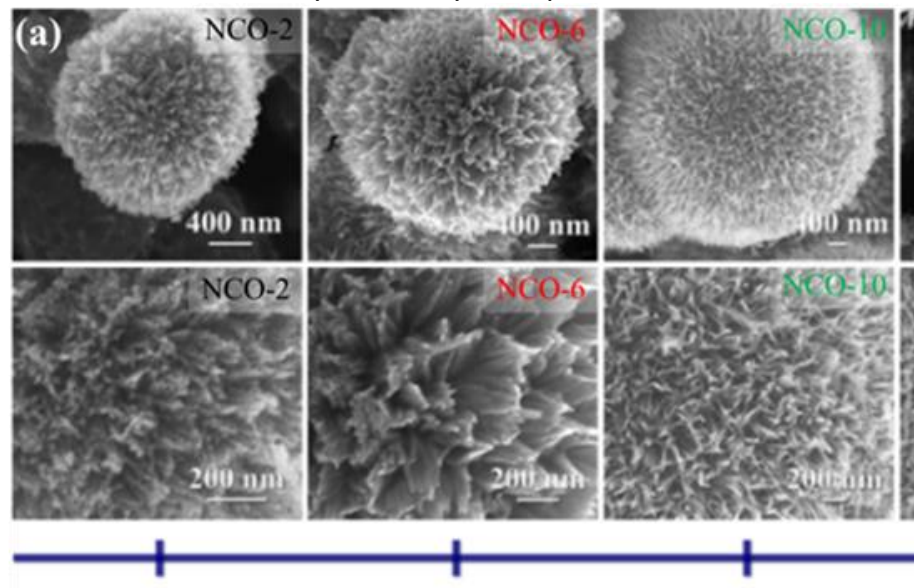

Increasing hydrothermal reaction time
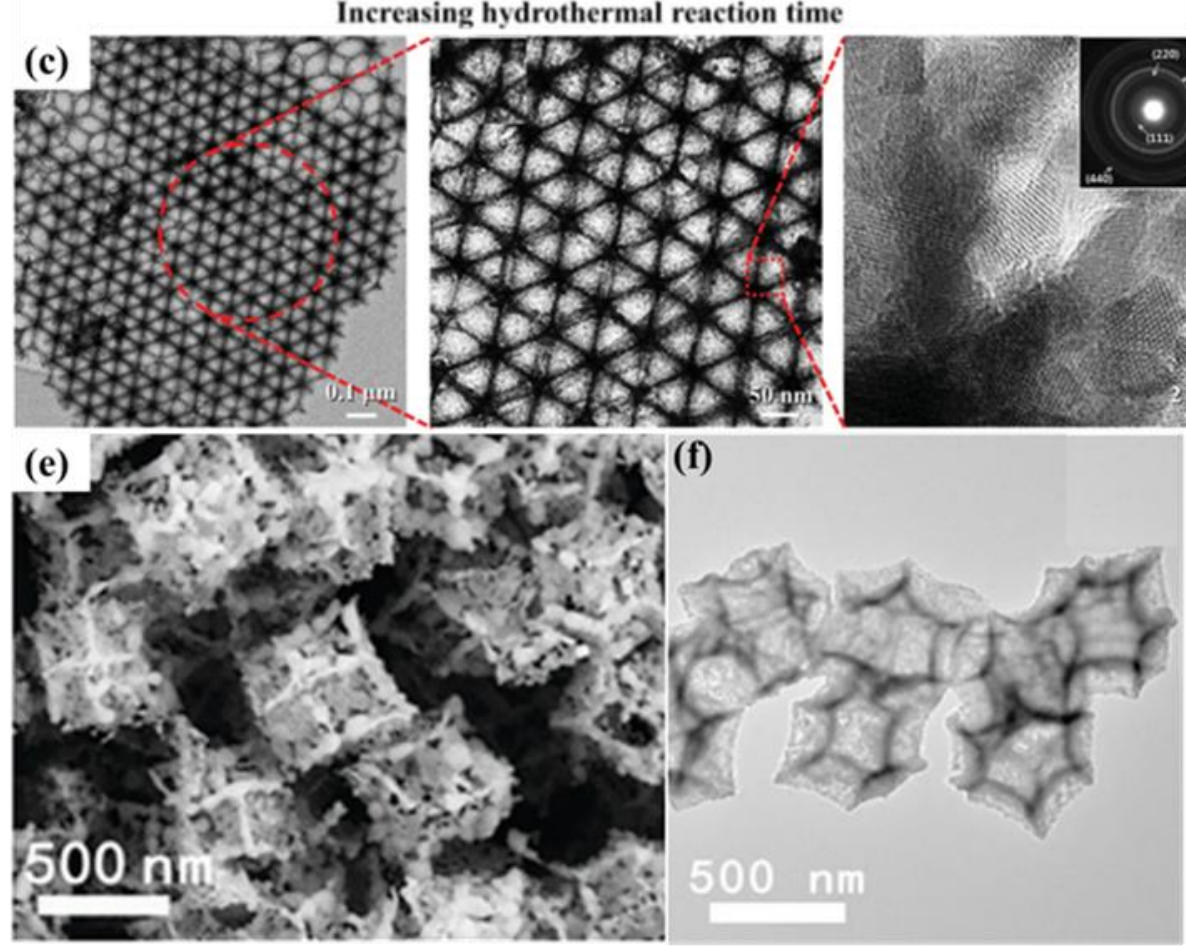
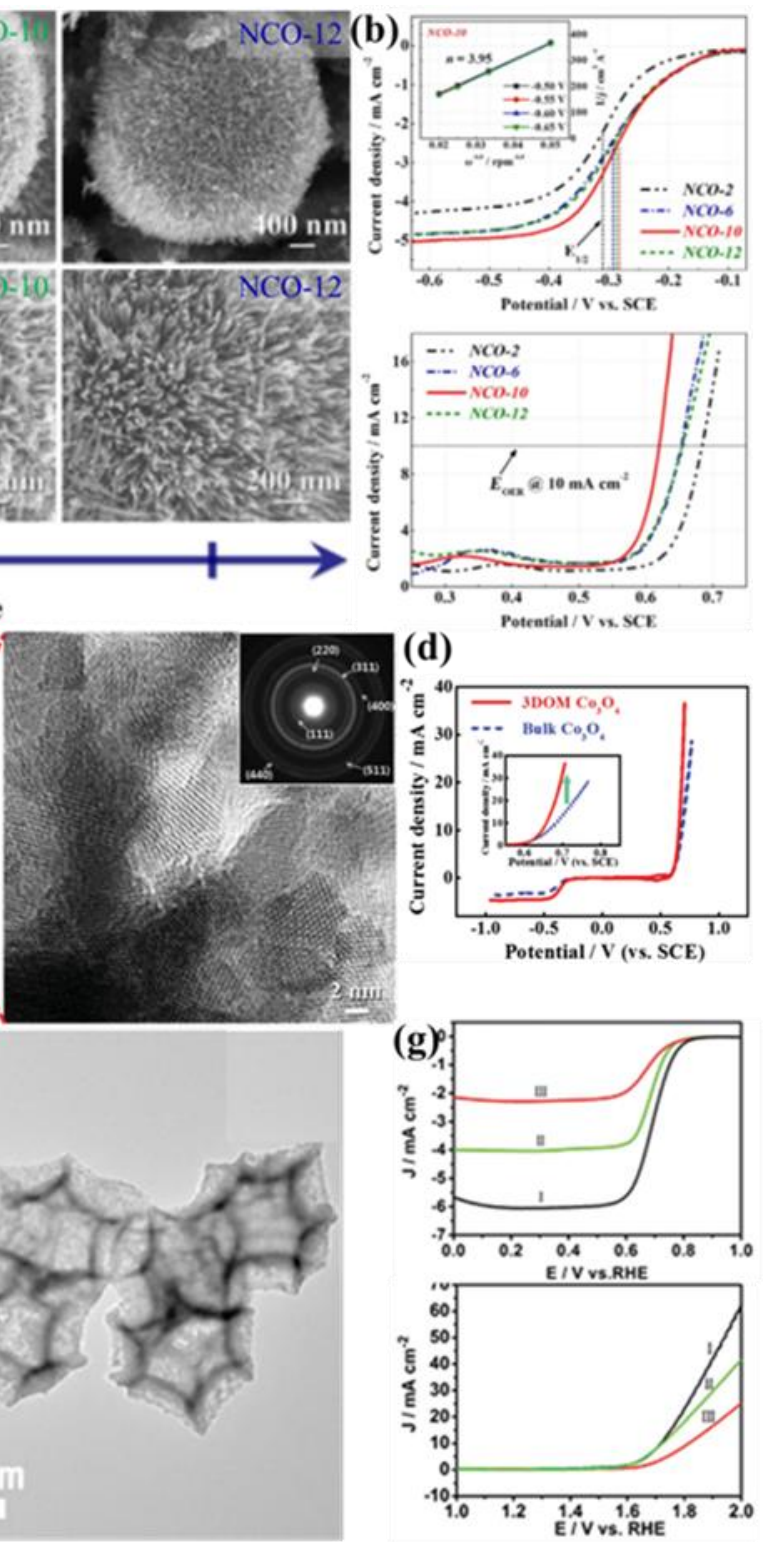

Figure 5. (a) Morphology and surface needles of $\mathrm{NiCO}_{2} \mathrm{O}_{4}$ formed at various hydrothermal reaction times of 2, 6, 10, and $12 \mathrm{~h}$ (NCO2, NCO-6, NCO-10, and NCO-12, respectively); (b) Corresponding OER and ORR curves in $0.1 \mathrm{M} \mathrm{KOH}$ solution. ${ }^{79}$ Copyright 2017, John Wiley \& Sons Inc. (c) Transmission electron microscope (TEM) images of 3D porous $\mathrm{Co}_{3} \mathrm{O}_{4}$ prepared using a polystyrene template (inset: corresponding selected area electron diffraction (SAED) pattern; (d) Comparison of OER/ORR performance in 0.1 $\mathrm{M} \mathrm{KOH}$ solution between the bulk and 3D ordered porous $\mathrm{Co}_{3} \mathrm{O}_{4} .{ }^{85}$ Copyright 2016, John Wiley \& Sons Inc. (e) Field emission

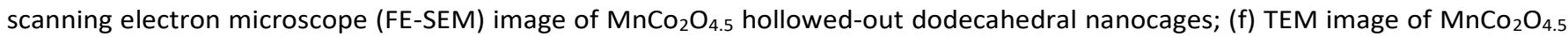
dodecahedrons; (g) ORR and OER polarization curves of $\mathrm{MnCo}_{2} \mathrm{O}_{4.5}$ hollowed-out dodecahedral nanocages (I), $\mathrm{MnCO}_{2} \mathrm{O}_{4.5}$ dodecahedra (II), and ZIF-67 (III) at 1600 rpm in $0.1 \mathrm{M} \mathrm{KOH}$ solution. ${ }^{75}$ Copyright 2018, John Wiley \& Sons Inc..

been proved by considerable efforts on shape-controlled synthesis to tailor the ORR activity of noble Pt metal. ${ }^{87-91}$ In nonadsorbing electrolytes such as perchloric acid, the ORR activity of low-index facets in single crystalline Pt is known to follow the order $(110)>(111)>(100)$ facets; ${ }^{87}$ while in the adsorbing electrolytes such as sulfuric acid, the(100) facets exhibit higher activity than their (111) counterparts instead, as sulfate anions strongly adsorb onto the (111) facets, blocking the sites. ${ }^{88}$ Hence, atomic-level-engineering of the surface structure can be used to precisely manipulate the exposure of active sites and subsequently enhance the corresponding electrocatalytic activity. ${ }^{92}$ He et al. highlighted the facet-dependent electrocatalytic activity of $\mathrm{MnO}$ nanocrystals for the OER/ORR in $0.1 \mathrm{M} \mathrm{KOH}$ solution. The $\mathrm{MnO}(100)$ facets with higher adsorption energy of $\mathrm{O}$ species can greatly promote the electrocatalytic activity [Figure 6(a-d)]. ${ }^{93}$ Cho et al. developed a micrometer-sized polyhedral bismuth ruthenate pyrochlore $(\mathrm{P}$ $B R O)$ for ZABs, which achieved highly improved catalytic activity 
by the development of (100), (110), and (111) planes, regardless of particle size. The ZAB based on P-RBO also performed outstanding than the benchmark $\mathrm{Pt} / \mathrm{IrO}_{2}$ system. ${ }^{94}$ Plausible active sites for the ORR and OER that occur

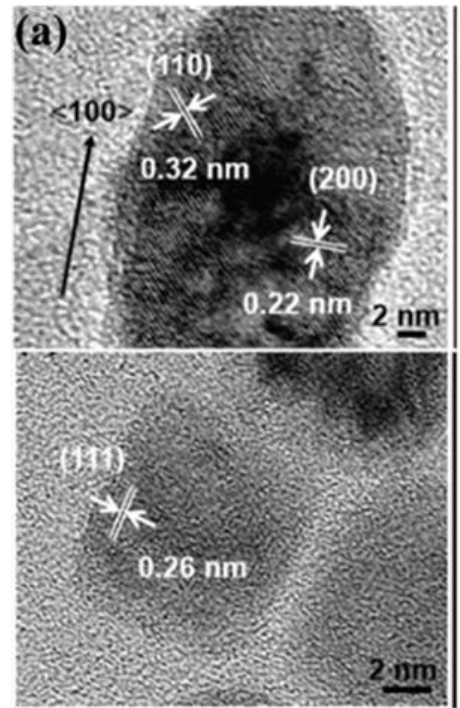

(b)
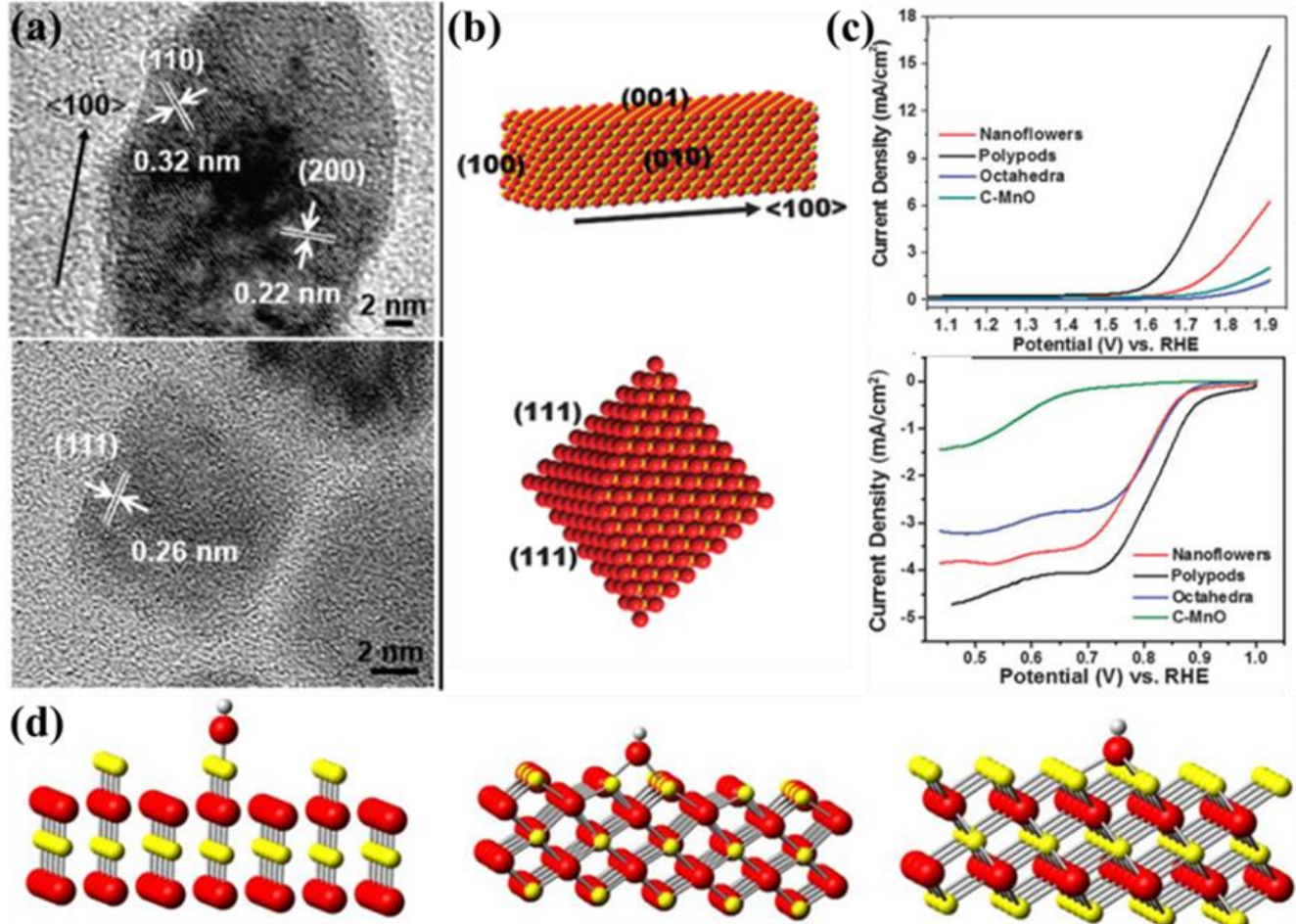

(100)

(e)
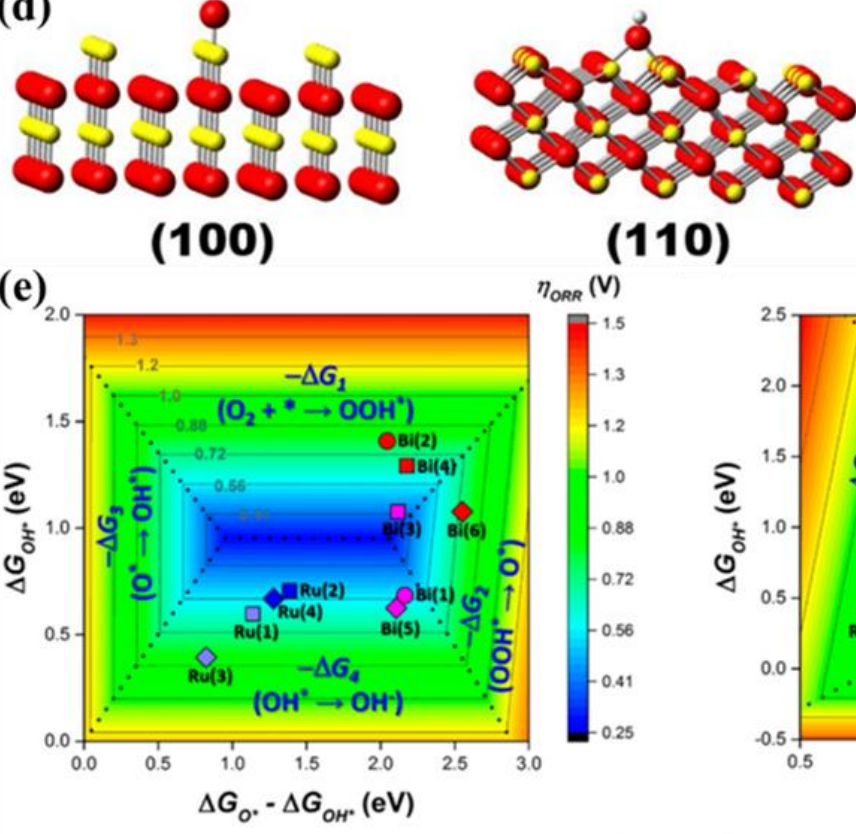

(110)

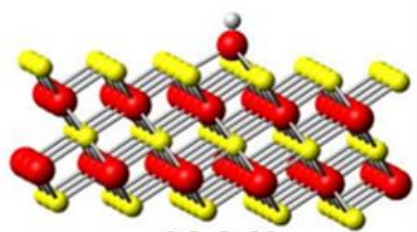

(111)

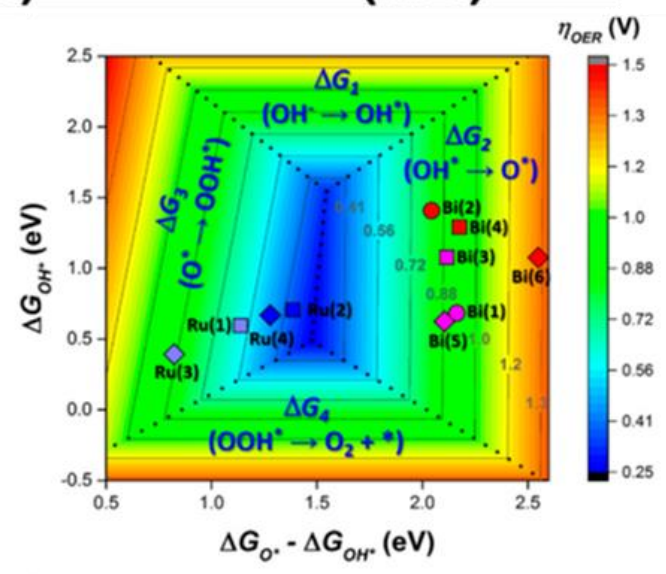

$\mathrm{Bi}(1):(100) \mathrm{Bi}(0 \mathrm{ML})$ Bi(2): (100) Bi (0.5 ML) Bi(3): (110) Bi $(0 \mathrm{ML}) \quad \mathrm{Bi}(4):(110) \mathrm{Bi}(0.5 \mathrm{ML}) \diamond \mathrm{Bi}(5):(111) \mathrm{Bi}(0 \mathrm{ML})$

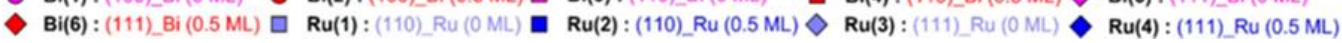

Figure 6. (a) TEM images of MnO single rod (upper) and octahedral nanoparticle (lower); (b) Schematic illustration indicating the growth direction and exposed planes of $\mathrm{MnO}$ nanorods and $\mathrm{MnO}$ octahedral nanoparticles, where $\mathrm{O}$ is red and $\mathrm{Mn}$ is yellow; (c) Current density Vs. potential for different morphologies; (d) Representative $\mathrm{OH}^{*}$ adsorbate species on different $\mathrm{MnO}$ lattice surfaces. $\mathrm{H}$ is in white, $\mathrm{O}$ is in red, and $\mathrm{Mn}$ is in yellow. ${ }^{93}$ Copyright 2015 , Royal Society of Chemistry. (e) Density functional theory (DFT) calculation results of the low-index facets on the surface of the P-BRO including (100), (110), and (111) planes during the ORR and OER are respectively displayed in the form of 2D maps of theoretical overpotential $(\eta)$ as a function of the adsorption free energies (i.e., $\Delta G_{\mathrm{O}^{*}}-\Delta G_{\mathrm{OH}^{*}}$ and $\Delta G_{\mathrm{OH}^{*}}$. ${ }^{94}$ Copyright 2018, American Chemical Society.

on the polyhedral bismuth ruthenate pyrochlore (P-BRO) were located by a two-dimensional (2D) map of theoretical overpotentials based on two descriptors of the adsorption free energies, $\Delta G_{\mathrm{OH}^{*}}$ and $\left(\Delta G_{\mathrm{O}^{*}}-\Delta G_{\mathrm{OH}^{*}}\right)$ [Figure 6(e)]. It was found that the $\mathrm{Bi}(3)$ and $\mathrm{Ru}(4)$ surfaces exhibited the best ORR and OER performance with the lowest overpotential, respectively.
The traditional methodology for facet-control in nanoparticles is based on the interplay of crystal plane energy and surfactants. ${ }^{95-102}$ The principle behind this methodology is that certain crystal planes might be preferentially stabilized by strongly binding surfactants over other crystal planes. Thus, the shape of the nanocrystal might be fine-tuned by utilizing various possible combinations of surfactants and different crystal 
planes. Theoretical analysis of the surfactant-catalyst facet interaction is far behind the experimental work, however, while the usage of strongly binding surfactants is detrimental to

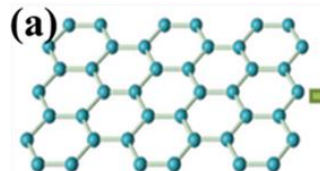
Graphene

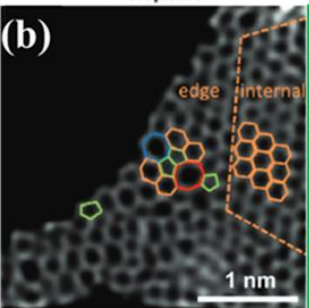

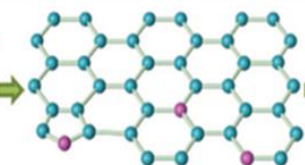
NG

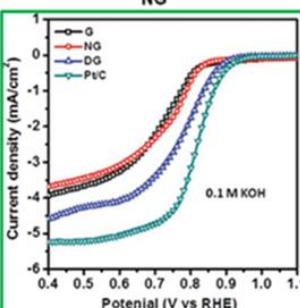

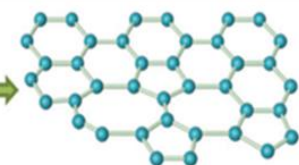

DG

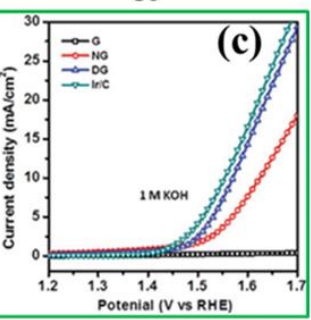

OER/ORR processes. Lee et al. therefore summarized strategies for achieving facet control in catalytic

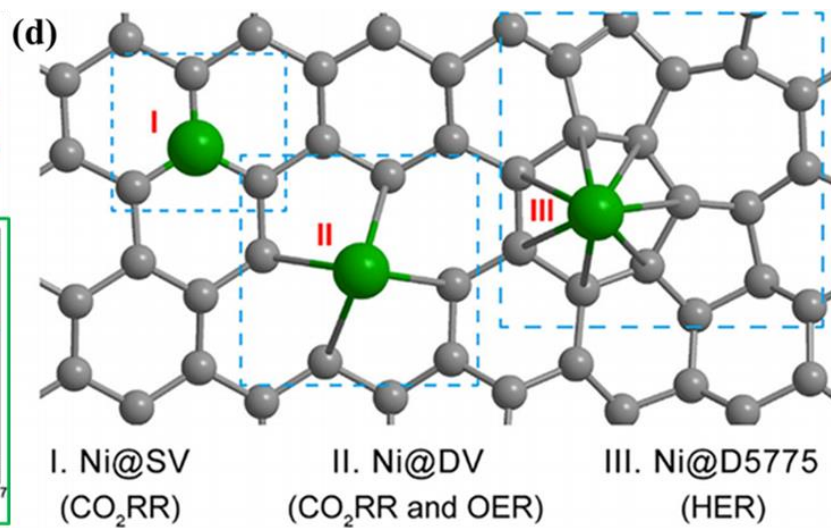

Figure 7. a) Schematic illustration of the formation of defect-rich graphene. (b) High-angle annular dark field (HAADF) image of DG with an acceleration voltage of $80 \mathrm{kV}$. The hexagons, pentagons, heptagons, and octagons are labeled in orange, green, blue, and red, respectively; (c) LSV curves of pristine graphene, NG, and DG for the ORR and OER in different alkaline solutions, respectively. ${ }^{103}$ Copyright 2016, John Wiley \& Sons Inc.. (d) Schematic structure of Ni atoms (green balls) coordinated in singlevacancy (SV), double-vacancy (DV), and 5775 (D5775) carbon (gray balls) defects; Ni@SV and Ni@DV are selective for the CO ${ }_{2}$ RR over the HER in neutral pH; and the latter is also active for the OER in alkaline media; Ni@D5775 was identified as the active site for the HER in acidic electrolyte. ${ }^{104-106}$ Copyright 2018, Elsevier Limited.

nanoparticles without using surfactants. ${ }^{107}$

\subsection{Defect Engineering}

In actual OER/ORR bifunctional nanostructured catalysts, it is impossible to prepare a truly perfect crystal without any defects. Due to a lack of deep understanding of the details of the OER/ORR processes and the necessary atomic characterization techniques, the effects of surface defects (disruptions or imperfections), which could also significantly alter the surface catalytic activity by tuning the surface electronic states, have long been ignored. Recently, more and more researchers have realized that surface defects, mainly in the form of single atom catalysts, heteroatom doping, cationic/anionic vacancies, and interstitial atoms, play more pivotal roles in achieving high catalytic activity than an intrinsically perfect surface. ${ }^{108-113}$ As shown in Figure 7(a-b), Yao et al. prepared defect-rich graphene (DG) with various types of defects (pentagons, heptagons, and octagons) via removing $\mathrm{N}$ atoms from $\mathrm{N}$-doped graphene (NG) through heat treatment. ${ }^{103}$ In comparison with perfect graphene, the OER/ORR catalytic activity of their NG sample was significantly improved. Interestingly, unlike previous explanations related to the enhancement of activity by $\mathrm{N}$ doping, Yao et al. found that even without $\mathrm{N}$ element, defect-rich graphene (pentagons, heptagons, and octagons) exhibited even higher OER/ORR performance [Figure 7(c)]. ${ }^{103}$ The ZAB test suggests that the DG sample has very stable charge and discharge voltages, high current and power density, which is comparable to Pt based ZAB. ${ }^{103}$ These results gave direct evidence that, as one kind of point defect, although doped $\mathrm{N}$ atoms could modify the electronic state of $\mathrm{C}$ or act as active sites for the OER/ORR, intrinsic carbon defects, such pentagonal, heptagonal, and octagonal carbon rings are more efficient for boosting the OER/ORR activity. Moreover, it was also found that the point defect active sites have excellent selectivity towards different reactions. ${ }^{103-105,} 114$ For example, the $\mathrm{Fe}-\mathrm{N}-\mathrm{C}$ single atom catalyst, whose active site is the $\mathrm{Fe}-\mathrm{N}_{4}-\mathrm{C}$ moiety, has been widely studied as an alternative oxygen reduction reaction (ORR) catalyst in place of Pt. ${ }^{115} \mathrm{Ni@SV} \mathrm{(SV:} \mathrm{single} \mathrm{vacancy)} \mathrm{and}$ $\mathrm{Ni@DV(DV:} \mathrm{double} \mathrm{vacancy)} \mathrm{were} \mathrm{found} \mathrm{to} \mathrm{be} \mathrm{selective} \mathrm{for} \mathrm{CO}_{2}$ reduction reactions $\left(\mathrm{CO}_{2} \mathrm{RR}\right)$ over hydrogen evolution reactions (HER) in neutral pH, and Ni@DV is also active towards the OER in alkaline media. ${ }^{105-106} \mathrm{Ni@D5775}$ was identified as the active site for the HER in acidic electrolyte [Figure 7(d)]. ${ }^{105}$ On account of their effectiveness and selectivity, research on the effect of defects in electrocatalysts has been a hot topic, and typical review papers are blossoming. ${ }^{40,42,103,114,116-117}$

Despite the limitations of characterization techniques, however, current research on defects has been mainly focused on point defects, although the effects of other one- or twodimensional defects in crystals, including grain boundaries, dislocations, and edges have still not been clearly stated and investigated. ${ }^{40,42,103,116-119}$ And due to the similar reason, the detailed effects of defects are complex and mostly unclear. However, defects would break uniform electronic states of perfect crystals, leading to unpredictable electronic coupling. Finally the electrostatic affinity at the defects towards different intermediates was adjusted.

\subsection{Effect of Strain}

Local lattice distortions or elastic strain in nanocrystal catalysts, which would induce slight changes in atomic-atomic bond lengths and modification of electronic states or atom rearrangements in the first or second subsurface strain layer, therefore could be seen as an important general strategy to adjust catalytic activity towards the OER/ORR. ${ }^{120}$ Moreover, the strain in the crystal would increase the energy level of the crystal; lead to instability in the strain-affected area, increasing the reaction activity towards $\mathrm{O}_{2}$ or $\mathrm{OH}^{-}$. Generally, surface strain 
inherently and universally exists in catalysts for two main reasons. First, compared with the inner atoms, the characteristic lower coordination or dangling bonds of surface atoms typically results in the emergence of

(a)

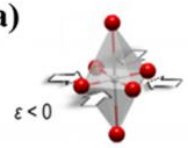

(b)
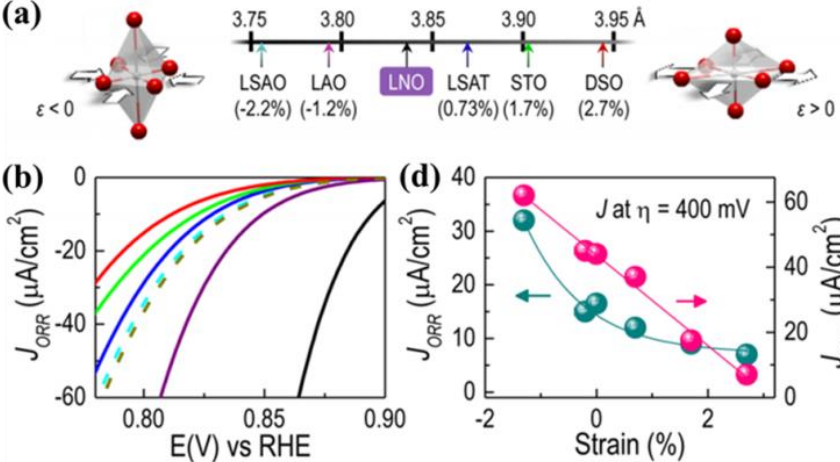

(c)

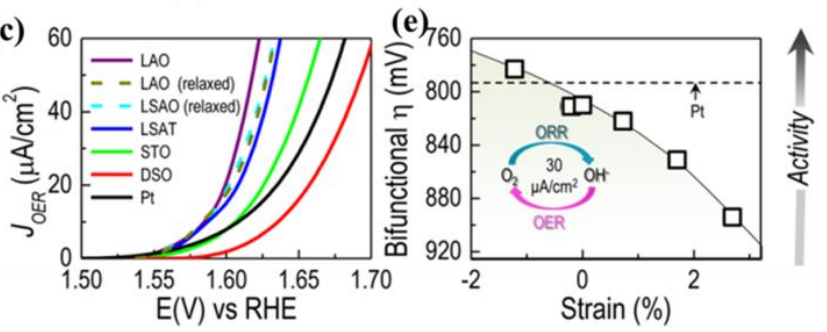

Figure 8. (a) Lattice parameters and associated biaxial strain for LNO on various substrates. Polarization curves for the (b) ORR and (c) OER on the strained LNO films. Strain-relaxed $(\varepsilon \sim 0 \%)$ films grown on $\mathrm{LaSrAlO}_{4}$ (LSAO) (10 nm in film thickness) and on LAO (100 nm in film thickness) as well as Pt films are used for comparison; LSAT, STO, and DSO represents $\left(\mathrm{LaAlO}_{3}\right)_{0.3}\left(\mathrm{SrAl}_{0.5} \mathrm{Ta}_{0.5} \mathrm{O}_{3}\right)_{0.7}, \mathrm{SrTiO}_{3}$, and $\mathrm{DySCO}_{3}$, respectively. (d) Current densities $(J)$ of both reactions at overpotentials of $\eta$ $=400 \mathrm{mV}(\mathrm{ORR}=0.823 \mathrm{~V}$, and OER $=1.623 \mathrm{~V})$ increase with compressive strain. (e) Bifunctional $\eta$ to achieve $30 \mu \mathrm{A} / \mathrm{cm}^{2}$ current density for both reactions show compressed $\mathrm{LaNiO}_{3}$ surpassing Pt. ${ }^{121}$ Copyright 2016, American Chemical Society.

internal strain in an attempt to minimize the surface energy. ${ }^{122}$ Second, nanocrystals should not be simply considered as small pieces of a bulk material. Unusual forms of structural disorder may exist and thus induce surface strain. ${ }^{120}$ Hence, besides defects, external forces, edges, core-shell structures, and fast or controlled growth of nanocrystals could also induce elastic strain on the surface or interfaces of catalysts. Correlating induced strain with catalytic performance is of fundamental importance for the design and construction of highly efficient catalytic nanomaterials, and tremendous progress has been made in this area in the past decade. ${ }^{123-125}$

Previous research on the effects of strain has been mostly on noble metals. An interesting example where the surface strain of $\mathrm{Pt}$ nanoparticles was tuned from compressive to tensile was achieved using a common Li-ion battery electrode materia ( $\mathrm{LiCoO}_{2}$ as the support). ${ }^{125} \mathrm{LiCoO}_{2}$ undergoes a large volume change when $\mathrm{Li}$ ions are repeatedly intercalated and extracted during electrochemical charge and discharge on its surface, leading to compressive and tensile strains for the 5-nm-thick layer of Pt deposited on $\mathrm{LiCoO}_{2}$, respectively. ${ }^{125}$ As early as in
2015, Yang et al., for the first time, found that epitaxial strain can tune the OER/ORR activity of perovskite $\mathrm{LaCoO}_{3}$ in alkaline solutions. They found that moderate tensile strain can further induce changes in the electronic structure, leading to increased catalytic activity towards both the OER and the ORR.

The resultant decrease in charge transfer resistance for movement to the electrolyte, however, reduces the overpotential in the ORR more notably than in the OER. Later, Lee et al. reported strained $\mathrm{LaNiO}_{3}$ (LNO) for the enhanced bifunctional ORR/OER catalysis. They used different latticemismatched substrates to control the degree of strain from $-2.2 \%$ to $2.7 \%$ [Figure $8(\mathrm{a})$ ]. ${ }^{121}, 126$ To systematically introduce strain into (001) LNO, epitaxial films (10 nm in thickness) were deposited by pulsed laser epitaxy on a range of latticemismatched substrates. They found that when $\mathrm{LaAlO}_{3}$ (LAO) was used as substrate, a small strain of $-1.2 \%$ produced in $\mathrm{LaNiO}_{3}$ can lead to enhanced bifunctional catalytic performance towards ORR/OER compared to other strained samples and pristine $\mathrm{LaNiO}_{3}$ [Figure 8(b,c)]. When ORR and OER activities under the overpotentials of $0.4 \mathrm{~V}$ are compared [Figure 8(d)], the bifunctional activity drastically increases with compressive strain. As a result, the $\mathrm{LaNiO}_{3}$ with the strain of $-1.2 \%$ has a bifunctional catalytic activity outperforming that of Pt [Figure 8(e)]. Interestingly, they also found that compressive strain could significantly and simultaneously enhance both the OER and the ORR reactions in $0.1 \mathrm{M} \mathrm{KOH}$ solution. Based on density functional theory (DFT) calculations, they ascribed the simultaneous enhancement of OER/ORR to the compressive strain-induced splitting of the $e_{\mathrm{g}}$ orbitals, which can create orbital asymmetry at the surface and lead to shifts in the $d$-band center relative to the Fermi level.

Generally, both Lee and Yang's explanations are based on the $d$ band model and the scaling effect. ${ }^{121,126-127}$ In its simplest interpretation, when a $d$-band transition metal is put under tensile strain, the interatomic spacing of the surface atoms increases, leading to less overlap of the $d$ orbitals and a narrower $d$-band width. As the number of $d$ electrons is unchanged, the fractional filling of the $d$ band remains constant, and the central moment of the $d$ band (the $d$-band center) shifts upward, leading to a strengthening of the adsorbate-surface interaction. Hence the general conclusion is that tensile strain leads to stronger binding towards all reactive intermediates, while compressive strain leads to weaker binding. This explanation, however, sometimes contradicts with experiment results. Just recently, as shown in Figure 9, Peterson et al. built a mechanics-based eigenstress model to rationalize the effect of strain on adsorbate-catalyst bonding. ${ }^{128}$ This model suggests that the sign of the binding-energy response to strain depends on the coupling of the adsorbate-induced eigenstress with the applied strain. Taking adsorption of $\mathrm{CH}_{2}$ on a $\mathrm{Cu}(001)$ surface as an example, if $\mathrm{CH}_{2}$ is adsorbed at the bridge site, tension makes the binding stronger (consistent with conventional explanations motivated by the $d$-band model), whereas if $\mathrm{CH}_{2}$ is adsorbed at the four-fold hollow sites, tension unexpectedly weakens the binding. They projected the $d$ band onto the two unique types of surface atom in the (110) surface and plotted the response of these projected $d$-band centers to strain [Figure 9(b)]; their deviation cannot be attributed simply to an opposite response 
of this electronic band to strain at differing sites. Instead, strain can make the binding either stronger or weaker, depending on the eigenstress characteristics of the adsorbate

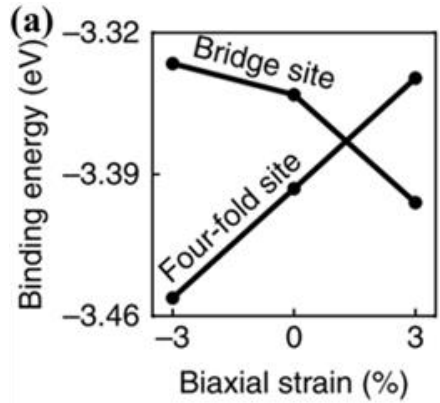

(b)

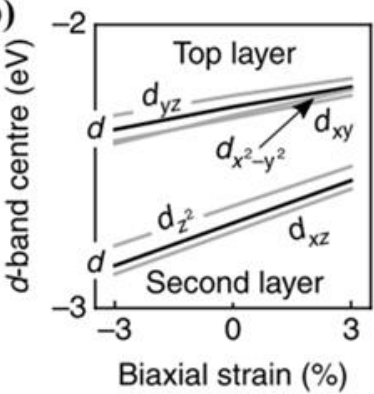

(c)

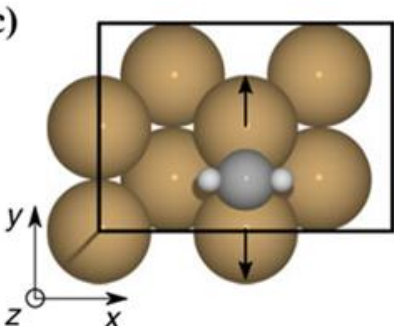

(d)

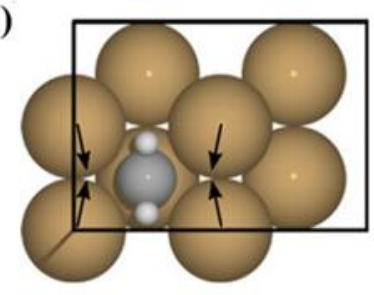

Figure 9. (a) Strain susceptibility of the energy of $\mathrm{CH}_{2}$ binding on a $\mathrm{Cu}(110)$ surface on both bridge and four-fold hollow sites. (b) Variations of the center (mean energy of states) of the $d$ orbitals projected onto the top- and second-layer atoms of the undistorted strained slab along different directions. (c) The inplane tensile strain on surface atoms induced by the presence of the adsorbate at the bridge site. (d) The in-plane compression strain on surface atoms induced by the presence of the adsorbate at the four-fold site. ${ }^{128}$ Copyright 2018, Springer Nature Publishing Group.

on the surface. Briefly speaking, if the intrinsic strain of the catalyst lattice is the same as the strain induced by adsorption of the intermediates, the strain would promote the adsorption, but otherwise, it hinders the reaction. Therefore the effect of strain is actually complex than for the simple $d$ band model.

\subsection{Formation of Composites}

The formation of composites has long been recognized as one important measure to achieve multifunctional performance or combine the merits of different materials. It is natural to entertain the concept of developing bifunctional catalysts from composites. The term "composite", however, is different from simply mixing different materials together; instead, here the composites are formed by atomic interactions, which would partially alter their electronic structure and thereby affect their OER/ORR catalytic activity. ${ }^{47}, 62,65,125,129-140$ Zhang et al. reported the OER/ORR catalytic performance of composites of $\mathrm{Co}_{9} \mathrm{~S}_{8}$ with different kinds of carbon, including $\mathrm{N}, \mathrm{S}$ co-doped porous carbon (NSPC) obtained at different annealing temperature and with different amounts of cobalt precursor, and N, S, co-doped carbon (NSC). ${ }^{62}$ As shown in Figure 10(a, b), simply by mixing NSPC with $\mathrm{Co}_{9} \mathrm{~S}_{8}$ ( $\mathrm{CO}_{9} \mathrm{~S}_{8} / \mathrm{NSPC}$ ), OER/ORR performance is improved, while the in-situ anchored $\mathrm{Co}_{9} \mathrm{~S}_{8} / \mathrm{NSPC} 9-45$ sample showed much lower OER/ORR overpotential $(\Delta E)$, indicating that the interaction between carbon and $\mathrm{CO}_{9} \mathrm{~S}_{8}$ plays a pivotal synergetic role in boosting
OER/ORR performance. More direct evidence is given by Kim et al. in Figure 10(d-f), ${ }^{139}$ who calculated the adsorption energy $\left(\Delta E_{\mathrm{ad}}\right)$ of $\mathrm{O}_{2}$ on perovskite $\mathrm{Sm}_{0.5} \mathrm{Sr}_{0.5} \mathrm{CoO}_{3-\delta}(\mathrm{SSC})$ and $\mathrm{SSC} / \mathrm{N}$ doped graphene composite (3DNG). The tendency of charge transfer from 3DNG to $\mathrm{O}_{2}$ leads to the increased bond length of the $\mathrm{O}_{2}$ molecular. The changes in the reaction free energy from single SSC [0.44 eV (endothermic)] to SSC/3DNG composite [-0.02 eV (exothermic)] resulted in enhanced OER/ORR performance.

Besides modification of the electronic structures, formation of composites, especially composites with porous carbon materials, also offers excellent mass/electron transfer paths and provide good durability in alkaline solution for catalytic cycles. ${ }^{138,} 140-143$ Moreover, the interface between the different components also has a great influence on the electrochemical activity and selectivity due to their intensive effects towards balancing the adsorption and desorption of the intermediates on the catalyst, as well as the transportation of intermediates, electrons, or adsorbents due to the strain effect originated from lattice mismatch. ${ }^{144-146}$ Hence, the formation of composites has great importance for boosting OER/ORR catalytic activity.

Moreover, it is well known that the electronic structure of a material is highly related to its structure and composition. Composition adjustment in catalysts has long been one of traditional strategies to modify the catalytic activity.

To replace noble metal catalysts, bimetallic nanoalloys of transition metals with carbon supports are one important group of ideal materials due to modified adsorption energy towards $\mathrm{OH}^{-}$and $\mathrm{O}_{2}$. NiCo-based electrocatalysts exhibit promising ORR/OER activity, as the carbon supports prevent aggregation of nanoalloy particles, although their ORR performance is still unsatisfactory. ${ }^{142,147} \mathrm{NiFe}$-based nanoalloy, on the other hand, shows good OER performance only in alkaline solution. ${ }^{148}$ Based on these results, Cho et al. synthesized ternary NiCoFe using pyrolyzation of $\mathrm{Fe}, \mathrm{Co}, \mathrm{Ni}$ metallocene precursors at $400^{\circ} \mathrm{C}$ and 100 bar pressure. ${ }^{149}$ The in-situ X-ray absorption (XAS) and DFT calculations have proved that $\mathrm{Co}$ and $\mathrm{Fe}$ atoms are the active sites of the ORR and the OER, respectively, while $\mathrm{Ni}$ element enhances the conductivity of the catalyst. Interestingly, single element $\mathrm{Co}$ and Fe have poor ORR and OER catalytic activity, indicating that alloying has changed their electronic structures. Another example was reported in 2015 by Johnston et al.. ${ }^{150} \mathrm{~A}$ series of crystalline $\mathrm{Ag}-\mathrm{Cu}$ nanoalloy particles with an average size of $2.58 \mathrm{~nm}$ and different compositions were deposited on nickel foam with the help of a laser. Compared with pure Ag or $\mathrm{Cu}$ metal, alloyed $\mathrm{Ag}_{50} \mathrm{Cu}_{50}$ and $\mathrm{Ag}_{25} \mathrm{Cu}_{75}$ nanoalloy catalysts possessed the best ORR and OER catalytic activity in alkaline solution, respectively [Figure 11(a-b)]. DFT calculations proved that the d-band center of $\mathrm{Ag}_{12} \mathrm{Cu}$ is much closer to the Fermi energy level than in the pure $\mathrm{Ag}_{13}$ clusters; while the $d$-band center of $\mathrm{Ag}_{50} \mathrm{Cu}_{50}$ is closer to the Fermi energy level than that of pure $\mathrm{Ag}$, as demonstrated in Figure 11 (c-d). The $\mathrm{O}_{2}$ adsorption energy increased from $-0.86 \mathrm{eV}$ in pure $\mathrm{Ag}_{13}$ clusters to $-1.36 \mathrm{eV}$ in the $\mathrm{Ag}_{12} \mathrm{Cu}$ clusters ( $\mathrm{Cu}$-shell). Therefore, it can be inferred that alloying $\mathrm{Cu}$ into $\mathrm{Ag}-\mathrm{Cu}$ nanoparticles has thermodynamic benefits for the $\mathrm{O}_{2}$ adsorption via electronic effects. The $d$-band center also has an influence on the adsorption of $\mathrm{OH}^{-}$and the ORR performance. ${ }^{150}$ The corresponding $Z A B$ cycling measurements shows the $\mathrm{Ag}_{50} \mathrm{Cu}_{50}$ 
catalyst exhibited a maximum power density of approximately $86.3 \mathrm{~mW} . \mathrm{cm}^{-2}$ and an acceptable cell
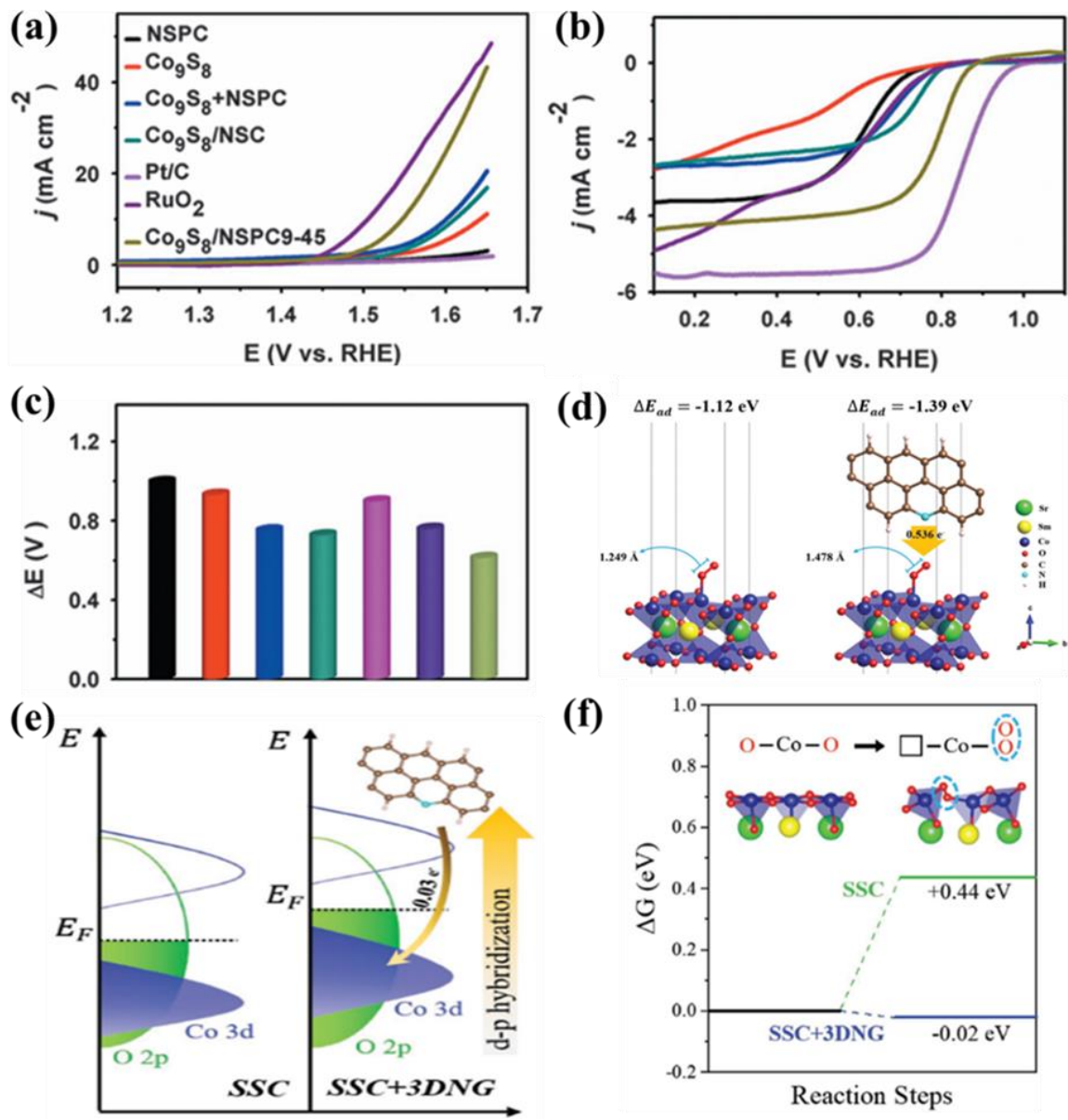

Figure 10. (a) OER polarization curves; (b) ORR polarization curves; (c) Potential gaps $(\triangle E)$ of $\mathrm{N}, \mathrm{S}$ co-doped porous $\mathrm{C}$ (NSPC), Cog $\mathrm{S}_{8}$ $\mathrm{Co}_{9} \mathrm{~S}_{8}+\mathrm{NSPC}, \mathrm{Co}_{9} \mathrm{~S}_{8} / \mathrm{NSPC}, \mathrm{Pt} / \mathrm{C}, \mathrm{RuO}_{2}$, and $\mathrm{Co}_{9} \mathrm{~S}_{8} / \mathrm{NSPC}-45$ (annealed at $900{ }^{\circ} \mathrm{C}$ with $45 \mathrm{mg}$ cobalt precursor). 62 Copyright 2016 , Springer Nature Publishing Group. (d) The model and calculated adsorption energy of $\mathrm{O}_{2}$ on SSC SSC/3DNG composite. The adsorption energy $\left(\Delta E_{\mathrm{ad}}\right)$ and bond length of $\mathrm{O}_{2}$ are shown at the top of each model; (e) Schematic band diagrams of SSC and SSC/3DNG composite. The electron transfer from 3DNG enhances the orbital hybridization between Co $3 d$ and $O 2 p$, and enhances the OER activity; (f) The change in the free energy, $\Delta G$, shows that each reaction from SSC to SSC/3DNG is endothermic or exothermic, respectively. ${ }^{139}$ Copyright 2018 , John Wiley \& Sons Inc..

voltage at $0.863 \mathrm{~V}$ for current densities up to $100 \mathrm{~mA} \cdot \mathrm{cm}^{-2}$. The round-trip efficiency reached $50 \%$ at a current density of 20 $\mathrm{mA} . \mathrm{cm}^{-2}{ }^{150}$ Besides the individual transition metal elements, doping a different element into other transition metal compounds also offers possibilities for further enhancing their bifunctional catalytic activity. ${ }^{66,81,124,151-153}$

\section{Conclusions and Remarks}

In general, it is much easier to deal with secondary Zinc-Air batteries (ZABs) relative to other metal-air batteries such as $\mathrm{Li}-$ air batteries. ${ }^{154}$ All the components of alkaline electrolyte based ZABs are moderately stable towards moisture, and all the reactions can be carried out under ambient air conditions. Therefore, the manufacturing process for ZABs is less stringent and cheaper than that for $\mathrm{Li}$-air batteries. Therefore, as an important and relatively mature technology, ZABs hold the greatest promise for future energy storage applications. Despite their early start and great potential, however, the wide applications of alkaline based ZABs has been impeded by problems such as the unavoidable corrosion of zinc anode, the volatile and corrosive nature of alkaline electrolyte, as well as expensive, poor performance OER/ORR catalysts. The former two problems, however, could be simply overcome by the concept of mechanically rechargeable batteries in real applications, where the zinc electrode and electrolyte are physically removed and replaced, ${ }^{26}$ and solid/quasi-solid electrolyte techniques. ${ }^{11-12,} 136$ Hence, the ultimate hindrance for this excellent energy storage technique has become the development of efficient and low-cost bifunctional catalysts that could significantly decrease the overpotential between charge and discharge to increase the energy utilization efficiency. Although in recent years, many high-performance non-precious-metal based bifunctional (OER/ORR) catalysts 
have been developed through engineering their chemical compositions, structures, or their interaction with the carbon
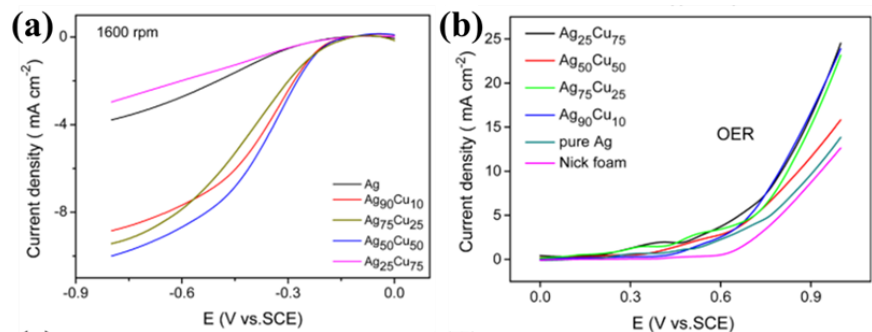

(c)

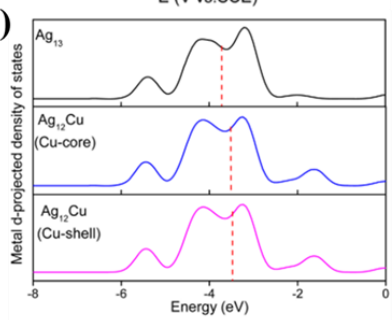

(d)

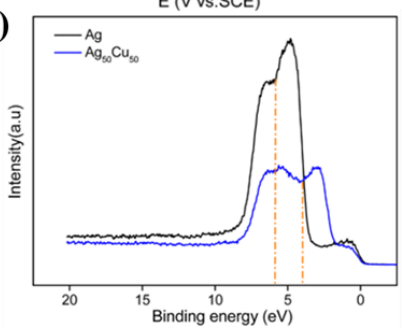

Figure 11. (a) ORR and (b) OER polarization curves of $\mathrm{Ag}$, $\mathrm{Ag}_{90} \mathrm{Cu}_{50}, \mathrm{Ag}_{75} \mathrm{Cu}_{25}, \mathrm{Ag}_{50} \mathrm{Cu}_{50}$, and $\mathrm{Ag}_{25} \mathrm{Cu}_{75}$ nanoalloys in $0.1 \mathrm{M}$ $\mathrm{KOH}$ solution at $1600 \mathrm{rpm}$. (c) $d$-projected density of states for the $\mathrm{Ag}_{13}, \mathrm{Ag}_{12} \mathrm{Cu}$ (Cu-core), and $\mathrm{Ag}_{12} \mathrm{Cu}$ (Cu-shell) structures. (d) valence band spectrum (VBS) of $\mathrm{Ag}$ and $\mathrm{Ag}_{50} \mathrm{Cu}_{50}$ alloy. ${ }^{150}$ Copyright 2015, American Chemical Society.

support, their catalytic activity are still unsatisfactory. This paper has summarized the most recent progress in detailed strategies to significantly enhance the intrinsic OER/ORR activities of the non-precious-metal based catalysts.

(1) Although the OER/ORR mechanism has long been investigated, several issues are still ambiguous. For example, what is the main factor that affects the $\mathrm{O}_{2}$ adsorption mode, which finally leads to the different twoand four-electron ORR modes? The effect of the amorphous hydroxides layer that is formed at the initial stage during the OER/ORR needs to be further confirmed, while the effects of the bulk lattice (including structure, composition) towards the formation of this amorphous layer also need further investigations. Moreover, the catalytic active sites need to be identified in some bifunctional catalysts, such as the heteroatom-doped carbon and the interfaces of composites. Is there any other possible way to break the scaling effect by decoupling the binding energies of different intermediates during the OER/ORR procedures - for instance, by stabilizing $\mathrm{OOH}^{*}$ with respect to $\mathrm{OH}^{*}$ ? ${ }^{155}$ It is believed that with the development of operando characterization techniques, the OER/ORR procedures would be revealed more clearly, which this would definitely promote better catalytic activity towards the OER and ORR.

(2) There are generally two strategies to improve the activity of an electrocatalyst: (i) increasing the number of active sites on a given electrode or (ii) increasing the intrinsic activity of each active site. Among all the summarized strategies, the effects of defects and strain have been the two most active directions for further enhancing bifunctional catalytic activity. Further elucidation of the relationship between different defect structures and electronic structures would offer an excellent scaffold for further boosting their bifurcated catalytic activity towards the OER/ORR. Theoretical calculations can further guide researchers to design defect-rich nanocatalysts through prediction of the accurate electronic structures of various materials. By combining the rapid development of various advanced characterization methods experimental data and theoretical calculations, the positive effects of defects can be studied more clearly, and novel types of defects other than point defects and their corresponding effect on the OER/ORR may be discovered. An establishment of a database that showing corresponding relations between defect types and effect on catalytic activity is of great importance for developing of catalysts.

(3) The $d$-band model could explain most effects of electronic structure tuning, but not fully explain the strain-induced changes in the adsorption properties. Instead, the new theory that the strain effect could break the scaling relationship between the OER and the ORR provides new explanations. Nevertheless, precise quantification of the induced strain requires knowledge of the 3D positions of atoms in nanocatalysts with high accuracy, which is not easy to achieve with currently used techniques. In addition, the stability of strain during practical electrocatalytic processes also needs further investigation.

(4) The utilization of each single strategy always causes several effects, for example, heteroatom doping on surface of catalyst usually modifies the electronic structure due to the composition adjustment, while introducing point defects and local strains. Hence, the enhancement of catalytic activity towards the OER/ORR is actually a synergic effect of several strategies in most cases. Besides the stated strategies, any method that could alter atom configurations to induce electronic structure fluctuations could possibly balance the catalytic activity between the OER and ORR to achieve promotion of bifunctional catalytic activity.

(5) Since the OER/ORR procedures in the ZABs are tri-phase reactions in nature, the effective access of mass with the catalysts is also important for improving catalytic activity. Thereby the adjustment of hydrophobic/hydrophilic by different ligands could also significantly affect the catalytic activity. Moreover, the surface ligands may also alter surface electronic states and thus the intrinsic catalytic activity. Although no relevant reports in this field in current stage, it is highly believed this will be a hot topic in near future.

We believe that the combination of a series of theoretical and experimental work, together with the use of varies operando characterization techniques will further advance the development of highly efficient non-precious-metal based bifunctional ORR/OER electrocatalysts, and pave the way for commercial application of the alkaline based Zinc-Air battery in the near future.

\section{Conflicts of interest}


There are no conflicts to declare.

\section{Acknowledgements}

This work is supported by Australian Research Council (ARC) through a Discovery project (DP180101453). Dr. W. Li wants to thank the support from Discovery Early Career Researcher Award via DE180101478. We would like to thank Dr. Tania Silver for polishing the manuscript. The authors also want to thank the Institute for Superconducting and Electronic Materials (ISEM) at the University of Wollongong (UOW) for their support.

1 E. Hu and X.-Q. Yang, Nat. Mater., 2018, 17, 480-481.

2 Z. Wang, J. Huang, Z. Guo, X. Dong, Y. Liu, Y. Wang and Y. Xia, Joule, 2019, doi: 10.1016/j.joule.2019.02.012.

3 F. Wang, O. Borodin, T. Gao, X. Fan, W. Sun, F. Han, A. Faraone, J. A. Dura, K. Xu and C. Wang, Nat. Mater., 2018, 17, 543-549.

4 J. Yi, P. Liang, X. Liu, K. Wu, Y. Liu, Y. Wang, Y. Xia and J. Zhang, Energy Environ. Sci., 2018, 11, 3075-3095.

5 C. Xu, B. Li, H. Du and F. Kang, Angew. Chem. Intl. Ed., 2012, 124, 957-959.

6 W. G. Hardin, D. A. Slanac, X. Wang, S. Dai, K. P. Johnston and K. J. Stevenson, J. Phys. Chem, Lett., 2013, 4, 1254-1259.

7 M. H. Alfaruqi, V. Mathew, J. Gim, S. Kim, J. Song, J. P. Baboo, S. H. Choi and J. Kim, Chem. Mater., 2015, 27, 3609-3620.

8 D. U. Lee, J. Fu, M. G. Park, H. Liu, A. Ghorbani Kashkooli and Z. Chen, Nano Lett., 2016, 16, 1794-1802.

9 A. R. Mainar, O. Leonet, M. Bengoechea, I. Boyano, I. Meatza, A. Kvasha, A. Guerfi and J. Alberto Blázquez, Intl. J. Energy Res., 2016, 40, 1032-1049.

10 N. Zhang, F. Cheng, Y. Liu, Q. Zhao, K. Lei, C. Chen, X. Liu and J. Chen, J. Am. Chem. Soc., 2016, 138, 12894-12901.

11 J. Fu, Z. P. Cano, M. G. Park, A. Yu, M. Fowler and Z. Chen, Adv. Mater., 2017, 29, 1604685.

12 P. Gu, M. Zheng, Q. Zhao, X. Xiao, H. Xue and H. Pang, J. Mater Chem. A, 2017, 5, 7651-7666.

13 Y. Li and H. Dai, Chem. Soc. Rev., 2014, 43, 5257-5275.

14 E. Davari and D. G. Ivey, Sustain. Energy Fuels, 2018, 2, 39-67.

15 H. D. Yoo, E. Markevich, G. Salitra, D. Sharon and D. Aurbach, Mater. Today, 2014, 17, 110-121.

16 J. Stamm, A. Varzi, A. Latz and B. Horstmann, J. Power Source, 2017, 360, 136-149.

17 Z. W. Seh, J. Kibsgaard, C. F. Dickens, I. Chorkendorff, J. K Nørskov and T. F. Jaramillo, Science, 2017, 355.

18 C. Chakkaravarthy, A. K. A. Waheed and H. V. K. Udupa, J. Power Source, 1981, 6, 203-228.

19 J. R. Goldstein and B. Koretz, IEEE Aero. Electronic Sys. Mag., 1993, 8, 34-38.

20 J. Goldstein, I. Brown and B. Koretz, J. Power Source, 1999, 80, 171-179.

21 E. Deiss, F. Holzer and O. Haas, Electrochim. Acta, 2002, 47, 39954010.

22 W. H. Zhu, B. A. Poole, D. R. Cahela and B. J. Tatarchuk, J. Appl. Electrochem., 2003, 33, 29-36.

23 S. I. Smedley and X. G. Zhang, J. Power Source, 2007, 165, 897904.

24 J. F. Parker, C. N. Chervin, I. R. Pala, M. Machler, M. F. Burz, J. W. Long and D. R. Rolison, Science, 2017, 356, 415-418.

25 C. Kim, B. Y. Ahn, T.-S. Wei, Y. Jo, S. Jeong, Y. Choi, I.-D. Kim and J. A. Lewis, ACS Nano, 2018.

26 L. Ma, S. Chen, Z. Pei, H. Li, Z. Wang, Z. Liu, Z. Tang, J. A. Zapien and C. Zhi, ACS Nano, 2018, 12, 8597-8605.

27 A. R. Mainar, E. Iruin, L. C. Colmenares, A. Kvasha, I. de Meatza M. Bengoechea, O. Leonet, I. Boyano, Z. Zhang and J. A. Blazquez, J. Energy Storage, 2018, 15, 304-328.
28 P. Tan, B. Chen, H. Xu, W. Cai, W. He, H. Zhang, M. Liu, Z. Shao and M. Ni, ACS Appl. Mater. Interfaces, 2018, 10, 36873-36881.

29 P. He, M. Yan, G. Zhang, R. Sun, L. Chen, Q. An and L. Mai, Adv. Energy Mater., 2017, 7, 1601920.

30 P. Hu, M. Yan, T. Zhu, X. Wang, X. Wei, J. Li, L. Zhou, Z. Li, L. Chen and L. Mai, ACS Appl. Mater. Interfaces, 2017, 9, 42717-42722.

31 B. Li, J. Quan, A. Loh, J. Chai, Y. Chen, C. Tan, X. Ge, T. S. A. Hor, Z. Liu, H. Zhang and Y. Zong, Nano Lett., 2017, 17, 156-163.

32 H.-F. Wang, C. Tang and Q. Zhang, Adv. Functn. Mater., 2018, 28, 1803329.

33 D. Yan, Y. Li, J. Huo, R. Chen, L. Dai and S. Wang, Adv. Mater., 2017, 29, 1606459

34 Y. Jiao, Y. Zheng, M. Jaroniec and S. Z. Qiao, Chem. Soc. Rev., 2015, 44, 2060-2086.

$35 \mathrm{~J} . \mathrm{Yi}, \mathrm{X}$. Liu, P. Liang, K. Wu, J. Xu, Y. Liu and J. Zhang, Organometallics, 2019, 38, 1186-1199.

36 P. Pei, K. Wang and Z. Ma, Appl. Energy, 2014, 128, 315-324.

37 H. Chen, T. N. Cong, W. Yang, C. Tan, Y. Li and Y. Ding, Prog. Nat. Sci., 2009, 19, 291-312.

38 D. O. Akinyele and R. K. Rayudu, Sustain. Energy Technol. Assessments, 2014, 8, 74-91.

39 G. Toussaint, P. Stevens, L. Akrour, R. Rouget and F. Fourgeot, ECS Trans., 2010, 28, 25-34.

40 B. Zakeri and S. Syri, Renew. Sustain. Energy Rev., 2015, 42, 569596.

41 V. Jülch, Appl. Energy, 2016, 183, 1594-1606

42 D. Wittmaier, T. Danner, N. Wagner and K. A. Friedrich, J. Appl.Electrochem., 2014, 44, 73-85.

43 J. Dixon In Energy storage for electric vehicles, 2010 IEEE International Conference on Industrial Technology, 14-17 March 2010; 2010; pp 20-26.

44 B. Dunn, H. Kamath and J.-M. Tarascon, Science, 2011, 334, 928935.

45 Z. Guo, C. Li, W. Li, H. Guo, X. Su, P. He, Y. Wang and Y. Xia, J. Mater. Chem. A, 2016, 4, 6282-6289.

46 R. Christensen, H. A. Hansen, C. F. Dickens, J. K. Nørskov and T. Vegge, J. Phys. Chem. C, 2016, 120, 24910-24916.

47 Z.-F. Huang, J. Wang, Y. Peng, C.-Y. Jung, A. Fisher and X. Wang, Adv. Energy Mater., 2017, 7, 1700544.

48 K. Fan, H. Zou, Y. Lu, H. Chen, F. Li, J. Liu, L. Sun, L. Tong, M. F. Toney, M. Sui and J. Yu, ACS Nano, 2018, 12, 12369-12379.

49 O. Mabayoje, A. Shoola, B. R. Wygant and C. B. Mullins, ACS Energy Lett., 2016, 1, 195-201.

50 M. Busch, N. B. Halck, U. I. Kramm, S. Siahrostami, P. Krtil and J. Rossmeisl, Nano Energy, 2016, 29, 126-135.

51 F. Meng, H. Zhong, D. Bao, J. Yan and X. Zhang, J. Am. Chem. Soc., 2016, 138, 10226-10231.

52 S. Gupta, L. Qiao, S. Zhao, H. Xu, Y. Lin, S. V. Devaguptapu, X. Wang, M. T. Swihart and G. Wu, Adv. Energy Mater., 2016, 6, 1601198.

53 T. Ling, D.-Y. Yan, Y. Jiao, H. Wang, Y. Zheng, X. Zheng, J. Mao, X.W. Du, Z. Hu, M. Jaroniec and S.-Z. Qiao, Nat. Commun., 2016, 7, 12876.

54 Y. Liang, Y. Li, H. Wang, J. Zhou, J. Wang, T. Regier and H. Dai, Nat Mater., 2011, 10, 780.

55 C. Ma, N. Xu, J. Qiao, S. Jian and J. Zhang, Intl. J. Hydrogen Energy, 2016, 41, 9211-9218.

56 Z. Chen, A. Yu, R. Ahmed, H. Wang, H. Li and Z. Chen, Electrochim. Acta, 2012, 69, 295-300.

57 K. Chakrapani, G. Bendt, H. Hajiyani, T. Lunkenbein, M. T. Greiner, L. Masliuk, S. Salamon, J. Landers, R. Schlögl, H. Wende, R. Pentcheva, S. Schulz and M. Behrens, ACS Catal., 2018, 8, 12591267.

58 J.-I. Jung, M. Risch, S. Park, M. G. Kim, G. Nam, H.-Y. Jeong, Y. Shao-Horn and J. Cho, Energy Environ. Sci., 2016, 9, 176-183.

59 W. Liu, J. Zhang, Z. Y. Bai, G. P. Jiang, M. Li, K. Feng, L. Yang, Y. L. Ding, T. W. Yu, Z. W. Chen and A. P. Yu, Adv. Functn. Mater. 2018, 28, 1706675 
60 A. Li, Y. X. Li, L. M. C. Luo, J. Yin, Y. Zhao, C. L. Xu, F. Y. Cheng, Y. Yang, P. X. Xi and S. J. Guo, Adv. Functn. Mater., 2017, 27, 1703779.

61 H.-X. Zhong, K. Li, Q. Zhang, J. Wang, F.-L. Meng, Z.-J. Wu, J.-M. Yan and X.-B. Zhang, NPG Asia Mater., 2016, 8, e308.

62 Y. Zhan, G. Du, S. Yang, C. Xu, M. Lu, Z. Liu and J. Y. Lee, ACS Appl. Mater. Interfaces, 2015, 7, 12930-12936.

63 Q. Wang, L. Shang, R. Shi, X. Zhang, G. I. N. Waterhouse, L.-Z. Wu, C.-H. Tung and T. Zhang, Nano Energy, 2017, 40, 382-389.

64 Y. Fan, S. Ida, A. Staykov, T. Akbay, H. Hagiwara, J. Matsuda, K. Kaneko and T. Ishihara, Small, 2017, 13, 1700099.

65 X. Qin, Z. Wang, J. Han, Y. Luo, F. Xie, G. Cui, X. Guo and X. Sun Chem. Commun., 2018, 54, 7693-7696.

66 H. Li, Q. Li, P. Wen, T. B. Williams, S. Adhikari, C. Dun, C. Lu, D. Itanze, L. Jiang, D. L. Carroll, G. L. Donati, P. M. Lundin, Y. Qiu and S. M. Geyer, Adv. Mater., 2018, 30, 1705796.

67 J.-C. Li, P.-X. Hou, S.-Y. Zhao, C. Liu, D.-M. Tang, M. Cheng, F. Zhang and H.-M. Cheng, Energy Environ. Sci., 2016, 9, 3079-3084.

68 G.-L. Chai, K. Qiu, M. Qiao, M.-M. Titirici, C. Shang and Z. Guo, Energy Environ. Sci., 2017, 10, 1186-1195.

69 Q. Liu, Y. Wang, L. Dai and J. Yao, Adv. Mater., 2016, 28, 30003006.

70 T. Maiyalagan, K. A. Jarvis, S. Therese, P. J. Ferreira and A. Manthiram, Nat. Commun., 2014, 5, 3949.

71 Y. Gorlin, B. Lassalle-Kaiser, J. D. Benck, S. Gul, S. M. Webb, V. K. Yachandra, J. Yano and T. F. Jaramillo, J. Am. Chem. Soc., 2013, 135, 8525-8534.

72 Y. Gorlin and T. F. Jaramillo, J. Am. Chem. Soc., 2010, 132, 1361213614.

73 I. M. Mosa, S. Biswas, A. M. El-Sawy, V. Botu, C. Guild, W. Song, R. Ramprasad, J. F. Rusling and S. L. Suib, J. Mater. Chem. A, 2016 4, 620-631.

74 A. Paulraj, Y. Kiros, M. Göthelid and M. Johansson, Catalysts, 2018, 8, 328 .

75 Z. Bai, J. Heng, Q. Zhang, L. Yang and F. Chang, Adv. Energy Mater., 2018, 8, 1802390

76 X. Cai, B. Y. Xia, J. Franklin, B. Li, X. Wang, Z. Wang, L. Chen, J. Lin, L. Lai and Z. Shen, J. Mater. Chem. A, 2017, 5, 2488-2495.

77 V. M. Dhavale and S. Kurungot, ACS Catal., 2015, 5, 1445-1452.

78 D. U. Lee, J.-Y. Choi, K. Feng, H. W. Park and Z. Chen, Adv. Energy Mater., 2014, 4, 1301389.

79 D. U. Lee, M. G. Park, Z. P. Cano, W. Ahn and Z. Chen, ChemSusChem, 2018, 11, 406-414.

80 D. U. Lee, J. Scott, H. W. Park, S. Abureden, J.-Y. Choi and Z. Chen, Electrochem. Commun., 2014, 43, 109-112.

81 Y.-J. Li, L. Cui, P.-F. Da, K.-W. Qiu, W.-J. Qin, W.-B. Hu, X.-W. Du, K. Davey, T. Ling and S.-Z. Qiao, Adv. Mater., 2018, 30, 1804653.

82 S. V. Devaguptapu, S. Hwang, S. Karakalos, S. Zhao, S. Gupta, D. $\mathrm{Su}, \mathrm{H}$. Xu and G. Wu, ACS Appl. Mater. Interfaces, 2017, 9, 4456744578.

83 Y. Meng, W. Song, H. Huang, Z. Ren, S.-Y. Chen and S. L. Suib, J. Am. Chem. Soc., 2014, 136, 11452-11464.

84 T. Y. Ma, S. Dai, M. Jaroniec and S. Z. Qiao, J. Am. Chem. Soc., 2014, 136, 13925-13931

85 M. G. Park, D. U. Lee, M. H. Seo, Z. P. Cano and Z. Chen, Small, 2016, 12, 2707-2714

86 K. Huang, Y. Sun, Y. Zhang, X. Wang, W. Zhang and S. Feng, Adv. Mater., 2019, 0, 1801430

87 N. M. Marković, R. R. Adžić, B. D. Cahan and E. B. Yeager, J. Electroanal. Chem., 1994, 377, 249-259.

88 M. E. Gamboa-Aldeco, E. Herrero, P. S. Zelenay and A. Wieckowski, J. Electroanal. Chem., 1993, 348, 451-457.

89 C. Wang, H. Daimon, Y. Lee, J. Kim and S. Sun, J. Am. Chem. Soc., 2007, 129, 6974-6975.

90 Z. Chen, M. Waje, W. Li and Y. Yan, Angew. Chem. Intl. Ed., 2007, $119,4138-4141$.

91 Z. Quan, Y. Wang and J. Fang, Accounts Chem. Res., 2013, 46, $191-$ 202.
92 H. G. Yang, C. H. Sun, S. Z. Qiao, J. Zou, G. Liu, S. C. Smith, H. M. Cheng and G. Q. Lu, Nature, 2008, 453, 638.

93 C.-H. Kuo, I. M. Mosa, S. Thanneeru, V. Sharma, L. Zhang, S Biswas, M. Aindow, S. Pamir Alpay, J. F. Rusling, S. L. Suib and J. He, Chem. Commun., 2015, 51, 5951-5954.

94 J. Park, M. Shirai, G. Y. Jung, S. O. Park, M. Park, J. Ryu, S. K. Kwak and J. Cho, ACS Catal., 2018, 8, 9647-9655.

95 H. Lee, S. E. Habas, S. Kweskin, D. Butcher, G. A. Somorjai and P. Yang, Angew. Chem. Intl. Ed., 2006, 45, 7824-7828.

96 S. Chen, Z. L. Wang, J. Ballato, S. H. Foulger and D. L. Carroll, J. Am. Chem. Soc., 2003, 125, 16186-16187.

97 F. Dumestre, B. Chaudret, C. Amiens, P. Renaud and P. Fejes, Science, 2004, 303, 821-823.

98 Y. Sun and Y. Xia, Science, 2002, 298, 2176-2179.

99 X. Peng, L. Manna, W. Yang, J. Wickham, E. Scher, A. Kadavanich and A. P. Alivisatos, Nature, 2000, 404, 59.

100 M. S. Bakshi, Crystal Growth \& Design, 2016, 16, 1104-1133.

101 C. H. Lee, M. Kim, T. Kim, A. Kim, J. Paek, J. W. Lee, S.-Y. Choi, K. Kim, J.-B. Park and K. Lee, J. Am. Chem. Soc., 2006, 128, 93269327.

102 D. J. Milliron, S. M. Hughes, Y. Cui, L. Manna, J. Li, L.-W. Wang and A. Paul Alivisatos, Nature, 2004, 430, 190.

103 K. Lee, M. Kim and H. Kim, J. Mater. Chem., 2010, 20, 37913798.

104 Y. Jia, L. Zhang, A. Du, G. Gao, J. Chen, X. Yan, C. L. Brown and X. Yao, Adv. Mater., 2016, 28, 9532-9538.

105 K. Jiang and H. Wang, Chem, 2018, 4, 194-195.

106 L. Zhang, Y. Jia, G. Gao, X. Yan, N. Chen, J. Chen, M. T. Soo, B. Wood, D. Yang, A. Du and X. Yao, Chem, 2018, 4, 285-297.

107 K. Jiang, S. Siahrostami, A. J. Akey, Y. Li, Z. Lu, J. Lattimer, Y. Hu, C. Stokes, M. Gangishetty, G. Chen, Y. Zhou, W. Hill, W.-B. Cai, D. Bell, K. Chan, J. K. Nørskov, Y. Cui and H. Wang, Chem, 2017, 3, 950-960.

108 K. Gong, F. Du, Z. Xia, M. Durstock and L. Dai, Science, 2009, 323, 760-764.

109 J. Liang, Y. Jiao, M. Jaroniec and S. Z. Qiao, Angew. Chem. Intl. Ed., 2012, 51, 11496-11500.

110 Y. Meng, D. Voiry, A. Goswami, X. Zou, X. Huang, M. Chhowalla, Z. Liu and T. Asefa, J. Am. Chem. Soc., 2014, 136, 13554-13557.

111 K. Waki, R. A. Wong, H. S. Oktaviano, T. Fujio, T. Nagai, K. Kimoto and K. Yamada, Energy Environ. Sci., 2014, 7, 1950-1958.

112 G. Wu, K. L. More, C. M. Johnston and P. Zelenay, Science, 2011, 332, 443-447.

113 J. Zhang, Z. Zhao, Z. Xia and L. Dai, Nat. Nanotechnol., 2015, 10, 444.

114 Y. Zhang, L. Guo, L. Tao, Y. Lu and S. Wang, Small Methods, 2019, 0, 1800406.

115 H. T. Chung, D. A. Cullen, D. Higgins, B. T. Sneed, E. F. Holby, K. L. More and P. Zelenay, Science, 2017, 357, 479-484.

116 Z. Zhao, M. Li, L. Zhang, L. Dai and Z. Xia, Adv. Mater., 2015, 27, 6834-6840.

117 A. Wang, J. Li and T. Zhang, Nat. Rev. Chem., 2018, 2, 65-81.

118 Z. Zhao and Z. Xia, ACS Catal., 2016, 6, 1553-1558.

119 P. Chen, T. Zhou, L. Xing, K. Xu, Y. Tong, H. Xie, L. Zhang, W. Yan, W. Chu, C. Wu and Y. Xie, Angew. Chem. Intl. Ed., 2017, 56, 610-614

120 B. Gilbert, F. Huang, H. Zhang, G. A. Waychunas and J. F. Banfield, Science, 2004, 305, 651-654

121 B. Medasani and I. Vasiliev, Surface Sci., 2009, 603, 20422046.

122 M. Luo and S. Guo, Nat. Rev. Mater., 2017, 2, 17059.

123 A. Grimaud, K. J. May, C. E. Carlton, Y.-L. Lee, M. Risch, W. T. Hong, J. Zhou and Y. Shao-Horn, Nat. Commun., 2013, 4, 2439.

124 H. Wang, S. Xu, C. Tsai, Y. Li, C. Liu, J. Zhao, Y. Liu, H. Yuan, F. Abild-Pedersen, F. B. Prinz, J. K. Nørskov and Y. Cui, Science, 2016 354, 1031-1036. 
125 J. R. Petrie, V. R. Cooper, J. W. Freeland, T. L. Meyer, Z. Zhang D. A. Lutterman and H. N. Lee, J. Am. Chem. Soc., 2016, 138, 2488-2491.

126 J. R. Petrie, H. Jeen, S. C. Barron, T. L. Meyer and H. N. Lee, J. Am. Chem. Soc., 2016, 138, 7252-7255.

127 K. A. Stoerzinger, W. S. Choi, H. Jeen, H. N. Lee and Y. ShaoHorn, J. Phys. Chem, Lett., 2015, 6, 487-492.

128 A. Khorshidi, J. Violet, J. Hashemi and A. A. Peterson, Nat. Catal., 2018, 1, 263-268

129 Z. Wang, S. Xiao, Y. An, X. Long, X. Zheng, X. Lu, Y. Tong and S. Yang, ACS Appl. Mater. Interfaces, 2016, 8, 13348-13359.

130 N. Xu, Y. Liu, X. Zhang, X. Li, A. Li, J. Qiao and J. Zhang, Sci. Rep., 2016, 6, 33590 .

131 Y. Zang, H. Zhang, X. Zhang, R. Liu, S. Liu, G. Wang, Y. Zhang and H. Zhao, Nano Res., 2016, 9, 2123-2137.

132 M. Zeng, Y. Liu, F. Zhao, K. Nie, N. Han, X. Wang, W. Huang, X. Song, J. Zhong and Y. Li, Adv. Functn. Mater., 2016, 26, 43974404.

133 J. Zhu, M. Xiao, Y. Zhang, Z. Jin, Z. Peng, C. Liu, S. Chen, J. Ge and W. Xing, ACS Catal., 2016, 6, 6335-6342.

134 X. Han, X. Wu, C. Zhong, Y. Deng, N. Zhao and W. Hu, Nano Energy, 2017, 31, 541-550.

135 P.-C. Li, C.-C. Hu, T.-H. You and P.-Y. Chen, Carbon, 2017, 111, 813-821

136 C.-Y. Su, H. Cheng, W. Li, Z.-Q. Liu, N. Li, Z. Hou, F.-Q. Bai, H.X. Zhang and T.-Y. Ma, Adv. Energy Mater., 2017, 7, 1602420.

137 M. Wang, T. Qian, J. Zhou and C. Yan, ACS Appl. Mater Interfaces, 2017, 9, 5213-5221.

138 Q. Wang, L. Shang, R. Shi, X. Zhang, Y. Zhao, G. I. N. Waterhouse, L.-Z. Wu, C.-H. Tung and T. Zhang, Adv. Energy Mater., 2017, 7, 1700467.

139 Y. Bu, G. Nam, S. Kim, K. Choi, Q. Zhong, J. Lee, Y. Qin, J. Cho and G. Kim, Small, 2018, 14, 1802767.

140 X. Liu, L. Wang, P. Yu, C. Tian, F. Sun, J. Ma, W. Li and H. Fu, Angew. Chem. Intl. Ed., 2018, 57, 16166-16170.

141 A. Mahmood, H. Tabassum, R. Zhao, W. Guo, W. Aftab, Z. Liang, Z. Sun and R. Zou, Small, 2018, 14, 1803500.

142 G. Fu, Y. Chen, Z. Cui, Y. Li, W. Zhou, S. Xin, Y. Tang and J. B. Goodenough, Nano Lett., 2016, 16, 6516-6522.

143 D. U. Lee, M. G. Park, H. W. Park, M. H. Seo, X. Wang and Z. Chen, ChemSusChem, 2015, 8, 3129-3138.

144 Q. Shao, P. Wang and X. Huang, Adv. Functn. Mater., 0 1806419.

145 N. M. Markovic, Nat. Mater., 2013, 12, 101

146 V. R. Stamenkovic, D. Strmcnik, P. P. Lopes and N. M. Markovic, Nat. Mater., 2016, 16, 57.

147 X. Liu, M. Park, M. G. Kim, S. Gupta, G. Wu and J. Cho, Angew. Chem. Intl. Ed., 2015, 54, 9654-9658.

148 M. Gong and H. Dai, Nano Res., 2015, 8, 23-39.

149 G. Nam, Y. Son, S. O. Park, W. C. Jeon, H. Jang, J. Park, S. Chae, Y. Yoo, J. Ryu, M. G. Kim, S. K. Kwak and J. Cho, Adv. Mater., 2018, 30, 1803372

150 X. Wu, F. Chen, Y. Jin, N. Zhang and R. L. Johnston, ACS Appl. Mater. Interfaces, 2015, 7, 17782-17791.

151 W. Wan, Q. Wang, L. Zhang, H.-W. Liang, P. Chen and S.-H. Yu, J. Mater. Chem. A, 2016, 4, 8602-8609.

152 M. Yu, Z. Wang, C. Hou, Z. Wang, C. Liang, C. Zhao, Y. Tong, X Lu and S. Yang, Adv. Mater., 2017, 29, 1602868.

153 T. Tian, M. Zheng, J. Lin, X. Meng and Y. Ding, Chem. Commun., 2019, 55, 1044-1047.

154 J.-S. Lee, S. Tai Kim, R. Cao, N.-S. Choi, M. Liu, K. T. Lee and J. Cho, Adv. Energy Mater., 2011, 1, 34-50.

155 A. D. Doyle, J. H. Montoya and A. Vojvodic, ChemCatChem, $2015,7,738-742$

1 E. Hu and X.-Q. Yang, Nat. Mater., 2018, 17, 480-481.

2 Z. Wang, J. Huang, Z. Guo, X. Dong, Y. Liu, Y. Wang and Y. Xia, Joule, 2019
3 F. Wang, O. Borodin, T. Gao, X. Fan, W. Sun, F. Han, A. Faraone, J. A. Dura, K. Xu and C. Wang, Nat. Mater., 2018, 17, 543-549.

4 J. Yi, P. Liang, X. Liu, K. Wu, Y. Liu, Y. Wang, Y. Xia and J. Zhang, Energy Environ. Sci., 2018, 11, 3075-3095.

5 C. Xu, B. Li, H. Du and F. Kang, Angewandte Chemie, 2012, 124, 957-959.

6 W. G. Hardin, D. A. Slanac, X. Wang, S. Dai, K. P. Johnston and K. J. Stevenson, J. Phys. Chem, Lett., 2013, 4, 1254-1259.

7 M. H. Alfaruqi, V. Mathew, J. Gim, S. Kim, J. Song, J. P. Baboo, S. H. Choi and J. Kim, Chem. Mater., 2015, 27, 3609-3620.

8 D. U. Lee, J. Fu, M. G. Park, H. Liu, A. Ghorbani Kashkooli and Z. Chen, Nano Lett., 2016, 16, 1794-1802.

9 A. R. Mainar, O. Leonet, M. Bengoechea, I. Boyano, I. Meatza, A. Kvasha, A. Guerfi and J. Alberto Blázquez, International Journal of Energy Research, 2016, 40, 1032-1049.

10 N. Zhang, F. Cheng, Y. Liu, Q. Zhao, K. Lei, C. Chen, X. Liu and J. Chen, J. Am. Chem. Soc., 2016, 138, 12894-12901.

11 J. Fu, Z. P. Cano, M. G. Park, A. Yu, M. Fowler and Z. Chen, Adv. Mater., 2017, 29, 1604685.

12 P. Gu, M. Zheng, Q. Zhao, X. Xiao, H. Xue and H. Pang, J. Mater. Chem. A, 2017, 5, 7651-7666

13 P. Pei, K. Wang and Z. Ma, Applied Energy, 2014, 128, 315-324.

14 H. Chen, T. N. Cong, W. Yang, C. Tan, Y. Li and Y. Ding, Progress in Natural Science, 2009, 19, 291-312.

15 D. O. Akinyele and R. K. Rayudu, Sustainable Energy Technologies and Assessments, 2014, 8, 74-91.

16 G. Toussaint, P. Stevens, L. Akrour, R. Rouget and F. Fourgeot, ECS Transactions, 2010, 28, 25-34.

17 B. Zakeri and S. Syri, Renewable and Sustainable Energy Reviews, 2015, 42, 569-596.

18 V. Jülch, Applied Energy, 2016, 183, 1594-1606

19 D. Wittmaier, T. Danner, N. Wagner and K. A. Friedrich, Journal of Applied Electrochemistry, 2014, 44, 73-85.

20 A. R. Mainar, E. Iruin, L. C. Colmenares, A. Kvasha, I. de Meatza, M. Bengoechea, O. Leonet, I. Boyano, Z. Zhang and J. A. Blazquez, Journal of Energy Storage, 2018, 15, 304-328.

21 J. Dixon In Energy storage for electric vehicles, 2010 IEEE International Conference on Industrial Technology, 14-17 March 2010; 2010; pp 20-26.

22 B. Dunn, H. Kamath and J.-M. Tarascon, Science, 2011, 334, 928935.

23 J. F. Parker, C. N. Chervin, I. R. Pala, M. Machler, M. F. Burz, J. W. Long and D. R. Rolison, Science, 2017, 356, 415-418.

24 E. Davari and D. G. Ivey, Sustainable Energy \& Fuels, 2018, 2, 3967.

25 H. D. Yoo, E. Markevich, G. Salitra, D. Sharon and D. Aurbach, Mater. Today, 2014, 17, 110-121.

26 Y. Li and H. Dai, Chem. Soc. Rev., 2014, 43, 5257-5275.

27 C. Chakkaravarthy, A. K. A. Waheed and H. V. K. Udupa, J. Power Source, 1981, 6, 203-228.

28 J. R. Goldstein and B. Koretz, IEEE Aerospace and Electronic Systems Magazine, 1993, 8, 34-38.

29 J. Goldstein, I. Brown and B. Koretz, J. Power Source, 1999, 80, 171-179.

30 E. Deiss, F. Holzer and O. Haas, Electrochimica Acta, 2002, 47, 3995-4010.

31 W. H. Zhu, B. A. Poole, D. R. Cahela and B. J. Tatarchuk, Journal of Applied Electrochemistry, 2003, 33, 29-36. 
32 S. I. Smedley and X. G. Zhang, J. Power Source, 2007, 165, $897-$ 904.

33 C. Kim, B. Y. Ahn, T.-S. Wei, Y. Jo, S. Jeong, Y. Choi, I.-D. Kim and J. A. Lewis, ACS Nano, 2018.

34 L. Ma, S. Chen, Z. Pei, H. Li, Z. Wang, Z. Liu, Z. Tang, J. A. Zapien and C. Zhi, ACS Nano, 2018, 12, 8597-8605.

35 P. Tan, B. Chen, H. Xu, W. Cai, W. He, H. Zhang, M. Liu, Z. Shao and M. Ni, ACS Appl. Mater. Interfaces, 2018, 10, 36873-36881.

36 P. He, M. Yan, G. Zhang, R. Sun, L. Chen, Q. An and L. Mai, Adv. Energy Mater., 2017, 7, 1601920.

37 P. Hu, M. Yan, T. Zhu, X. Wang, X. Wei, J. Li, L. Zhou, Z. Li, L. Chen and L. Mai, ACS Appl. Mater. Interfaces, 2017, 9, 42717-42722.

38 B. Li, J. Quan, A. Loh, J. Chai, Y. Chen, C. Tan, X. Ge, T. S. A. Hor, Z. Liu, H. Zhang and Y. Zong, Nano Lett., 2017, 17, 156-163.

39 H.-F. Wang, C. Tang and Q. Zhang, Adv. Functn. Mater., 2018, 28, 1803329.

40 D. Yan, Y. Li, J. Huo, R. Chen, L. Dai and S. Wang, Adv. Mater., 2017, 29, 1606459

41 Z. W. Seh, J. Kibsgaard, C. F. Dickens, I. Chorkendorff, J. K. Nørskov and T. F. Jaramillo, Science, 2017, 355.

42 Y. Jiao, Y. Zheng, M. Jaroniec and S. Z. Qiao, Chem. Soc. Rev., 2015, 44, 2060-2086.

43 J. Yi, X. Liu, P. Liang, K. Wu, J. Xu, Y. Liu and J. Zhang, Organometallics, 2019, 38, 1186-1199.

44 J. Stamm, A. Varzi, A. Latz and B. Horstmann, J. Power Source, 2017, 360, 136-149.

45 Z. Guo, C. Li, W. Li, H. Guo, X. Su, P. He, Y. Wang and Y. Xia, J. Mater. Chem. A, 2016, 4, 6282-6289.

46 R. Christensen, H. A. Hansen, C. F. Dickens, J. K. Nørskov and T. Vegge, J. Phys. Chem. C, 2016, 120, 24910-24916.

47 Z.-F. Huang, J. Wang, Y. Peng, C.-Y. Jung, A. Fisher and X. Wang, Adv. Energy Mater., 2017, 7, 1700544.

48 K. Fan, H. Zou, Y. Lu, H. Chen, F. Li, J. Liu, L. Sun, L. Tong, M. F. Toney, M. Sui and J. Yu, ACS Nano, 2018.

49 O. Mabayoje, A. Shoola, B. R. Wygant and C. B. Mullins, ACS Energy Lett., 2016, 1, 195-201.

50 M. Busch, N. B. Halck, U. I. Kramm, S. Siahrostami, P. Krtil and J. Rossmeisl, Nano Energy, 2016, 29, 126-135.

51 T. Maiyalagan, K. A. Jarvis, S. Therese, P. J. Ferreira and A. Manthiram, Nat. Commun., 2014, 5, 3949.

52 F. Meng, H. Zhong, D. Bao, J. Yan and X. Zhang, J. Am. Chem. Soc., 2016, 138, 10226-10231.

53 S. Gupta, L. Qiao, S. Zhao, H. Xu, Y. Lin, S. V. Devaguptapu, X. Wang, M. T. Swihart and G. Wu, Adv. Energy Mater., 2016, 6, 1601198.

54 T. Ling, D.-Y. Yan, Y. Jiao, H. Wang, Y. Zheng, X. Zheng, J. Mao, X.W. Du, Z. Hu, M. Jaroniec and S.-Z. Qiao, Nat. Commun., 2016, 7, 12876.

55 Y. Liang, Y. Li, H. Wang, J. Zhou, J. Wang, T. Regier and H. Dai, Nat. Mater., 2011, 10, 780.

56 C. Ma, N. Xu, J. Qiao, S. Jian and J. Zhang, International Journal of Hydrogen Energy, 2016, 41, 9211-9218.

57 Z. Chen, A. Yu, R. Ahmed, H. Wang, H. Li and Z. Chen, Electrochimica Acta, 2012, 69, 295-300.

58 K. Chakrapani, G. Bendt, H. Hajiyani, T. Lunkenbein, M. T. Greiner, L. Masliuk, S. Salamon, J. Landers, R. Schlögl, H. Wende, R. Pentcheva, S. Schulz and M. Behrens, ACS Catal., 2018, 8, 1259-1267.

59 J.-I. Jung, M. Risch, S. Park, M. G. Kim, G. Nam, H.-Y. Jeong, Y. Shao-Horn and J. Cho, Energy Environ. Sci., 2016, 9, 176-183.
60 L. Wenwen, Z. Jing, B. Zhengyu, J. Gaopeng, L. Matthew, F. Kun, Y. Lin, D. Yuanli, Y. Tongwen, C. Zhongwei and Y. Aiping, Adv. Functn. Mater., 2018, 28, 1706675.

61 A. Li, L. Yuxuan, L. Mingchuan, Y. Jie, Z. Yong - Qing, X. Cailing, C. Fangyi, Y. Ying, X. Pinxian and G. Shaojun, Adv. Functn. Mater., 2017, 27, 1703779

62 H.-x. Zhong, K. Li, Q. Zhang, J. Wang, F.-I. Meng, Z.-j. Wu, J.-m. Yan and X.-b. Zhang, Npg Asia Materials, 2016, 8, e308.

63 Y. Zhan, G. Du, S. Yang, C. Xu, M. Lu, Z. Liu and J. Y. Lee, ACS Appl. Mater. Interfaces, 2015, 7, 12930-12936.

64 Q. Wang, L. Shang, R. Shi, X. Zhang, G. I. N. Waterhouse, L.-Z. Wu, C.-H. Tung and T. Zhang, Nano Energy, 2017, 40, 382-389.

65 Y. Fan, S. Ida, A. Staykov, T. Akbay, H. Hagiwara, J. Matsuda, K. Kaneko and T. Ishihara, Small, 2017, 13, 1700099.

66 X. Qin, Z. Wang, J. Han, Y. Luo, F. Xie, G. Cui, X. Guo and X. Sun, Chem. Commun., 2018, 54, 7693-7696.

67 H. Li, Q. Li, P. Wen, T. B. Williams, S. Adhikari, C. Dun, C. Lu, D. Itanze, L. Jiang, D. L. Carroll, G. L. Donati, P. M. Lundin, Y. Qiu and S. M. Geyer, Adv. Mater., 2018, 30, 1705796.

68 J.-C. Li, P.-X. Hou, S.-Y. Zhao, C. Liu, D.-M. Tang, M. Cheng, F. Zhang and H.-M. Cheng, Energy Environ. Sci., 2016, 9, 3079-3084.

69 G.-L. Chai, K. Qiu, M. Qiao, M.-M. Titirici, C. Shang and Z. Guo, Energy \& Environmental Science, 2017, 10, 1186-1195.

70 Q. Liu, Y. Wang, L. Dai and J. Yao, Adv. Mater., 2016, 28, 30003006.

71 I. M. Mosa, S. Biswas, A. M. El-Sawy, V. Botu, C. Guild, W. Song, R. Ramprasad, J. F. Rusling and S. L. Suib, J. Mater. Chem. A, 2016, 4, 620-631.

72 Y. Gorlin, B. Lassalle-Kaiser, J. D. Benck, S. Gul, S. M. Webb, V. K. Yachandra, J. Yano and T. F. Jaramillo, J. Am. Chem. Soc., 2013, 135, 8525-8534.

73 Y. Gorlin and T. F. Jaramillo, J. Am. Chem. Soc., 2010, 132, 1361213614.

74 A. Paulraj, Y. Kiros, M. Göthelid and M. Johansson, Catalysts, 2018, 8, 328.

75 Z. Bai, J. Heng, Q. Zhang, L. Yang and F. Chang, Adv. Energy Mater., 0, 1802390.

76 X. Cai, B. Y. Xia, J. Franklin, B. Li, X. Wang, Z. Wang, L. Chen, J. Lin, L. Lai and Z. Shen, J. Mater. Chem. A, 2017, 5, 2488-2495.

77 V. M. Dhavale and S. Kurungot, ACS Catal., 2015, 5, 1445-1452.

78 D. U. Lee, J.-Y. Choi, K. Feng, H. W. Park and Z. Chen, Adv. Energy Mater., 2014, 4, 1301389.

79 D. U. Lee, M. G. Park, Z. P. Cano, W. Ahn and Z. Chen, ChemSusChem, 2018, 11, 406-414.

80 D. U. Lee, J. Scott, H. W. Park, S. Abureden, J.-Y. Choi and Z. Chen, Electrochemistry Communications, 2014, 43, 109-112.

81 Y.-J. Li, L. Cui, P.-F. Da, K.-W. Qiu, W.-J. Qin, W.-B. Hu, X.-W. Du, K. Davey, T. Ling and S.-Z. Qiao, Adv. Mater., 2018, 30, 1804653.

82 S. V. Devaguptapu, S. Hwang, S. Karakalos, S. Zhao, S. Gupta, D. Su, H. Xu and G. Wu, ACS Appl. Mater. Interfaces, 2017, 9, 4456744578.

83 Y. Meng, W. Song, H. Huang, Z. Ren, S.-Y. Chen and S. L. Suib, J. Am. Chem. Soc., 2014, 136, 11452-11464.

84 T. Y. Ma, S. Dai, M. Jaroniec and S. Z. Qiao, J. Am. Chem. Soc., 2014, 136, 13925-13931.

85 M. G. Park, D. U. Lee, M. H. Seo, Z. P. Cano and Z. Chen, Small, 2016, 12, 2707-2714.

86 K. Huang, Y. Sun, Y. Zhang, X. Wang, W. Zhang and S. Feng, Adv. Mater., 0, 1801430. 
87 N. M. Marković, R. R. Adžić, B. D. Cahan and E. B. Yeager, Journal of Electroanalytical Chemistry, 1994, 377, 249-259.

88 M. E. Gamboa-Aldeco, E. Herrero, P. S. Zelenay and A. Wieckowski, Journal of Electroanalytical Chemistry, 1993, 348, 451457.

89 C. Wang, H. Daimon, Y. Lee, J. Kim and S. Sun, J. Am. Chem. Soc., 2007, 129, 6974-6975.

90 Z. Chen, M. Waje, W. Li and Y. Yan, Angewandte Chemie, 2007, 119, 4138-4141.

91 Z. Quan, Y. Wang and J. Fang, Accounts of Chemical Research, 2013, 46, 191-202.

92 H. G. Yang, C. H. Sun, S. Z. Qiao, J. Zou, G. Liu, S. C. Smith, H. M. Cheng and G. Q. Lu, Nature, 2008, 453, 638.

93 C.-H. Kuo, I. M. Mosa, S. Thanneeru, V. Sharma, L. Zhang, S. Biswas, M. Aindow, S. Pamir Alpay, J. F. Rusling, S. L. Suib and J. He, Chem. Commun., 2015, 51, 5951-5954.

94 J. Park, M. Shirai, G. Y. Jung, S. O. Park, M. Park, J. Ryu, S. K. Kwak and J. Cho, ACS Catal., 2018, 8, 9647-9655.

95 H. Lee, S. E. Habas, S. Kweskin, D. Butcher, G. A. Somorjai and P. Yang, Angew. Chem. Intl. Ed., 2006, 45, 7824-7828.

96 S. Chen, Z. L. Wang, J. Ballato, S. H. Foulger and D. L. Carroll, J. Am. Chem. Soc., 2003, 125, 16186-16187.

97 F. Dumestre, B. Chaudret, C. Amiens, P. Renaud and P. Fejes, Science, 2004, 303, 821-823.

98 Y. Sun and Y. Xia, Science, 2002, 298, 2176-2179.

99 X. Peng, L. Manna, W. Yang, J. Wickham, E. Scher, A. Kadavanich and A. P. Alivisatos, Nature, 2000, 404, 59.

100 M. S. Bakshi, Crystal Growth \& Design, 2016, 16, 1104-1133.

101 C. H. Lee, M. Kim, T. Kim, A. Kim, J. Paek, J. W. Lee, S.-Y. Choi, K. Kim, J.-B. Park and K. Lee, J. Am. Chem. Soc., 2006, 128, 9326-9327. 102 D. J. Milliron, S. M. Hughes, Y. Cui, L. Manna, J. Li, L.-W. Wang and A. Paul Alivisatos, Nature, 2004, 430, 190.

103 Y. Jia, L. Zhang, A. Du, G. Gao, J. Chen, X. Yan, C. L. Brown and X. Yao, Adv. Mater., 2016, 28, 9532-9538.

104 K. Jiang and H. Wang, Chem, 2018, 4, 194-195.

105 L. Zhang, Y. Jia, G. Gao, X. Yan, N. Chen, J. Chen, M. T. Soo, B. Wood, D. Yang, A. Du and X. Yao, Chem, 2018, 4, 285-297.

106 K. Jiang, S. Siahrostami, A. J. Akey, Y. Li, Z. Lu, J. Lattimer, Y. Hu, C. Stokes, M. Gangishetty, G. Chen, Y. Zhou, W. Hill, W.-B. Cai, D. Bell, K. Chan, J. K. Nørskov, Y. Cui and H. Wang, Chem, 2017, 3, 950960.

107 K. Lee, M. Kim and H. Kim, J. Mater. Chem., 2010, 20, 37913798.

108 K. Gong, F. Du, Z. Xia, M. Durstock and L. Dai, Science, 2009, 323, 760-764.

109 J. Liang, Y. Jiao, M. Jaroniec and S. Z. Qiao, Angew. Chem. Intl. Ed., 2012, 51, 11496-11500.

110 Y. Meng, D. Voiry, A. Goswami, X. Zou, X. Huang, M. Chhowalla, Z. Liu and T. Asefa, J. Am. Chem. Soc., 2014, 136, 1355413557.

111 K. Waki, R. A. Wong, H. S. Oktaviano, T. Fujio, T. Nagai, K. Kimoto and K. Yamada, Energy Environ. Sci., 2014, 7, 1950-1958.

112 G. Wu, K. L. More, C. M. Johnston and P. Zelenay, Science, 2011, 332, 443-447.

113 J. Zhang, Z. Zhao, Z. Xia and L. Dai, Nat. Nanotechnol., 2015, 10, 444.

114 Y. Zhang, L. Guo, L. Tao, Y. Lu and S. Wang, Small Methods, 0 1800406.
115 H. T. Chung, D. A. Cullen, D. Higgins, B. T. Sneed, E. F. Holby, K. L. More and P. Zelenay, Science, 2017, 357, 479-484.

116 Z. Zhao, M. Li, L. Zhang, L. Dai and Z. Xia, Adv. Mater., 2015, 27, 6834-6840.

117 A. Wang, J. Li and T. Zhang, Nat. Rev. Chem., 2018, 2, 65-81.

118 Z. Zhao and Z. Xia, ACS Catal., 2016, 6, 1553-1558.

119 P. Chen, T. Zhou, L. Xing, K. Xu, Y. Tong, H. Xie, L. Zhang, W. Yan, W. Chu, C. Wu and Y. Xie, Angew. Chem. Intl. Ed., 2017, 56, 610614.

120 B. Gilbert, F. Huang, H. Zhang, G. A. Waychunas and J. F. Banfield, Science, 2004, 305, 651-654.

121 J. R. Petrie, V. R. Cooper, J. W. Freeland, T. L. Meyer, Z. Zhang, D. A. Lutterman and H. N. Lee, J. Am. Chem. Soc., 2016, 138, 24882491.

122 B. Medasani and I. Vasiliev, Surface Sci., 2009, 603, 20422046.

123 M. Luo and S. Guo, Nature Reviews Materials, 2017, 2, 17059. 124 A. Grimaud, K. J. May, C. E. Carlton, Y.-L. Lee, M. Risch, W. T. Hong, J. Zhou and Y. Shao-Horn, Nat. Commun., 2013, 4, 2439.

125 H. Wang, S. Xu, C. Tsai, Y. Li, C. Liu, J. Zhao, Y. Liu, H. Yuan, F. Abild-Pedersen, F. B. Prinz, J. K. Nørskov and Y. Cui, Science, 2016, 354, 1031-1036.

126 J. R. Petrie, H. Jeen, S. C. Barron, T. L. Meyer and H. N. Lee, J. Am. Chem. Soc., 2016, 138, 7252-7255.

127 K. A. Stoerzinger, W. S. Choi, H. Jeen, H. N. Lee and Y. ShaoHorn, J. Phys. Chem, Lett., 2015, 6, 487-492.

128 A. Khorshidi, J. Violet, J. Hashemi and A. A. Peterson, Nat. Catal., 2018, 1, 263-268.

129 Z. Wang, S. Xiao, Y. An, X. Long, X. Zheng, X. Lu, Y. Tong and S. Yang, ACS Appl. Mater. Interfaces, 2016, 8, 13348-13359.

130 N. Xu, Y. Liu, X. Zhang, X. Li, A. Li, J. Qiao and J. Zhang, Sci. Rep., 2016, 6, 33590.

131 Y. Zang, H. Zhang, X. Zhang, R. Liu, S. Liu, G. Wang, Y. Zhang and H. Zhao, Nano Res., 2016, 9, 2123-2137.

132 M. Zeng, Y. Liu, F. Zhao, K. Nie, N. Han, X. Wang, W. Huang, X. Song, J. Zhong and Y. Li, Adv. Functn. Mater., 2016, 26, 4397-4404. 133 J. Zhu, M. Xiao, Y. Zhang, Z. Jin, Z. Peng, C. Liu, S. Chen, J. Ge and W. Xing, ACS Catal., 2016, 6, 6335-6342.

134 X. Han, X. Wu, C. Zhong, Y. Deng, N. Zhao and W. Hu, Nano Energy, 2017, 31, 541-550.

135 P.-C. Li, C.-C. Hu, T.-H. You and P.-Y. Chen, Carbon, 2017, 111, 813-821.

136 C.-Y. Su, H. Cheng, W. Li, Z.-Q. Liu, N. Li, Z. Hou, F.-Q. Bai, H.X. Zhang and T.-Y. Ma, Adv. Energy Mater., 2017, 7, 1602420.

137 M. Wang, T. Qian, J. Zhou and C. Yan, ACS Appl. Mater. Interfaces, 2017, 9, 5213-5221.

138 Q. Wang, L. Shang, R. Shi, X. Zhang, Y. Zhao, G. I. N. Waterhouse, L.-Z. Wu, C.-H. Tung and T. Zhang, Adv. Energy Mater., 2017, 7, 1700467.

139 Y. Bu, G. Nam, S. Kim, K. Choi, Q. Zhong, J. Lee, Y. Qin, J. Cho and G. Kim, Small, 2018, 14, 1802767.

140 X. Liu, L. Wang, P. Yu, C. Tian, F. Sun, J. Ma, W. Li and H. Fu, Angew. Chem. Intl. Ed., 2018, 57, 16166-16170.

141 A. Mahmood, H. Tabassum, R. Zhao, W. Guo, W. Aftab, Z. Liang, Z. Sun and R. Zou, Small, 2018, 14, 1803500.

142 G. Fu, Y. Chen, Z. Cui, Y. Li, W. Zhou, S. Xin, Y. Tang and J. B. Goodenough, Nano Lett., 2016, 16, 6516-6522.

143 D. U. Lee, M. G. Park, H. W. Park, M. H. Seo, X. Wang and Z. Chen, ChemSusChem, 2015, 8, 3129-3138. 
144 Q. Shao, P. Wang and X. Huang, Adv. Functn. Mater., 0, 1806419.

145 N. M. Markovic, Nat. Mater., 2013, 12, 101.

146 V. R. Stamenkovic, D. Strmcnik, P. P. Lopes and N. M. Markovic, Nat. Mater., 2016, 16, 57.

147 X. Liu, M. Park, M. G. Kim, S. Gupta, G. Wu and J. Cho, Angew. Chem. Intl. Ed., 2015, 54, 9654-9658.

148 M. Gong and H. Dai, Nano Res., 2015, 8, 23-39.

149 G. Nam, Y. Son, S. O. Park, W. C. Jeon, H. Jang, J. Park, S. Chae, Y. Yoo, J. Ryu, M. G. Kim, S. K. Kwak and J. Cho, Adv. Mater., 0, 1803372.

150 X. Wu, F. Chen, Y. Jin, N. Zhang and R. L. Johnston, ACS Appl. Mater. Interfaces, 2015, 7, 17782-17791.

151 W. Wan, Q. Wang, L. Zhang, H.-W. Liang, P. Chen and S.-H. Yu, J. Mater. Chem. A, 2016, 4, 8602-8609.

152 M. Yu, Z. Wang, C. Hou, Z. Wang, C. Liang, C. Zhao, Y. Tong, X. Lu and S. Yang, Adv. Mater., 2017, 29, 1602868.

153 T. Tian, M. Zheng, J. Lin, X. Meng and Y. Ding, Chem. Commun., 2018.

154 J.-S. Lee, S. Tai Kim, R. Cao, N.-S. Choi, M. Liu, K. T. Lee and J. Cho, Adv. Energy Mater., 2011, 1, 34-50.

155 A. D. Doyle, J. H. Montoya and A. Vojvodic, ChemCatChem, 2015, 7, 738-742. 